\title{
Clinical Practice Guideline: Nasal Irrigation for Chronic Rhinosinusitis in Adults
}

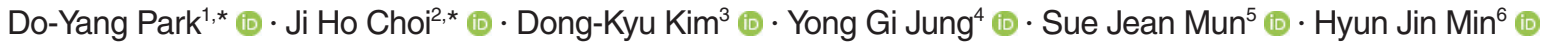

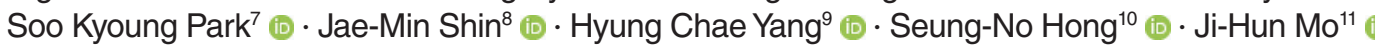 \\ ${ }^{1}$ Department of Otolaryngology, Ajou University School of Medicine, Suwon; ${ }^{2}$ Department of Otorhinolaryngology-Head and Neck Surgery, \\ Soonchunhyang University Bucheon Hospital, Soonchunhyang University College of Medicine, Bucheon; ${ }^{3}$ Department of \\ Otorhinolaryngology-Head and Neck Surgery, Chuncheon Sacred Heart Hospital, Hallym University College of Medicine, Chuncheon; \\ ${ }^{4}$ Department of Otorhinolaryngology-Head and Neck Surgery, Samsung Medical Center, Sungkyunkwan University School of Medicine, Seoul; \\ ${ }^{5}$ Department of Otorhinolaryngology-Head and Neck Surgery, Pusan National University Yangsan Hospital, Yangsan; ${ }^{6}$ Department of \\ Otorhinolaryngology-Head and Neck Surgery, Chung-Ang University College of Medicine, Seoul; ' Department of Otorhinolaryngology-Head \\ and Neck Surgery, Chungnam National University College of Medicine, Daejeon; ${ }^{8}$ Department of Otorhinolaryngology-Head and Neck Surgery, \\ Korea University College of Medicine, Seoul; ${ }^{9}$ Department of Otolaryngology-Head and Neck Surgery, Chonnam National University Medical \\ School and Chonnam National University Hospital, Gwangju; ${ }^{10}$ Department of Otorhinolaryngology-Head and Neck Surgery, SMG-SNU \\ Boramae Medical Center, Seoul National University College of Medicine, Seoul; ${ }^{11}$ Department of Otorhinolaryngology-Head and Neck Surgery, \\ Dankook University College of Medicine, Cheonan, Korea
}

The Korean Society of Otorhinolaryngology-Head and Neck Surgery and Korean Rhinologic Society appointed a guideline development group (GDG) to establish a clinical practice guideline, and the GDG developed a guideline for nasal irrigation for adult patients with chronic rhinosinusitis (CRS). The guideline focuses on knowledge gaps, practice variations, and clinical concerns associated with nasal irrigation. Nasal irrigation has been recommended as the first-line treatment for CRS in various guidelines, and its clinical effectiveness has been demonstrated through a number of studies with robust evidence. However, no guidelines have presented a consistent nasal irrigation method. Several databases, including OVID Medline, Embase, the Cochrane Library, and KoreaMed, were searched to identify all relevant papers using a predefined search strategy. When insufficient evidence was found, the GDG sought expert opinions and attempted to fill the evidence gap. Evidence-based recommendations for practice were ranked according to the American College of Physicians grading system. The committee developed 11 evidence-based recommendations. This guideline focuses on the evidence-based quality improvement opportunities deemed the most important by the GDG. Moreover, the guideline addresses whether nasal lavage helps treat CRS, what type of rinsing solution should be used, and the effectiveness of using additional medications to increase the therapeutic effect.

Keywords. Sinusitis; Treatment; Guideline; Saline Solution; Equipment; Steroids; Irrigation

\footnotetext{
- Received April 6, 2021

Revised June 14, 2021

Accepted June 17, 2021

- Corresponding author: Yong Gi Jung

Department of Otorhinolaryngology-Head and Neck Surgery, Samsung

Medical Center, Sungkyunkwan University School of Medicine,

81 Irwon-ro, Gangnam-gu, Seoul 06351, Korea

Tel: +82-2-3410-3579, Fax: +82-2-3410-3879

E-mail: ent.jyg@gmail.com
}

\footnotetext{
- Co-Corresponding author: Dong-Kyu Kim

Department of Otorhinolaryngology-Head and Neck Surgery, Chuncheon Sacred Heart Hospital, Hallym University College of Medicine, 77 Sakju-ro, Chuncheon 24253, Korea

Tel: +82-33-240-5180, Fax: +82-33-241-2909

E-mail: doctordk@naver.com

*These authors contributed equally to this work as first authors.
}

Copyright $\odot 2022$ by Korean Society of Otorhinolaryngology-Head and Neck Surgery.

This is an open-access article distributed under the terms of the Creative Commons Attribution Non-Commercial License (https://creativecommons.org/licenses/by-nc/4.0)

which permits unrestricted non-commercial use, distribution, and reproduction in any medium, provided the original work is properly cited. 


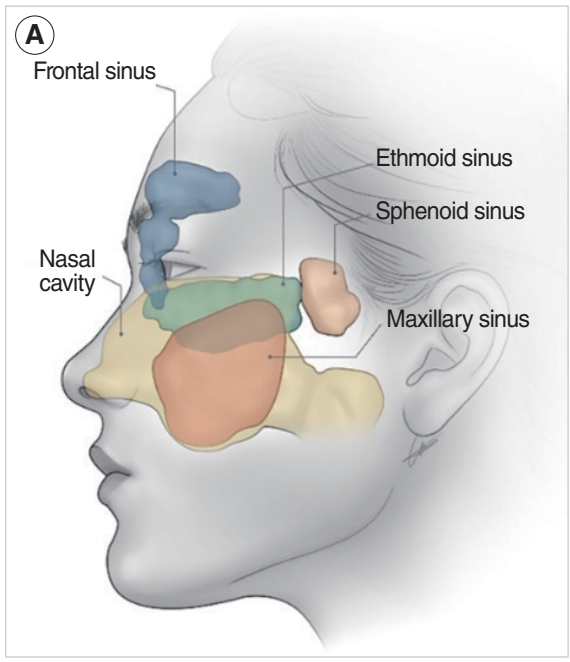

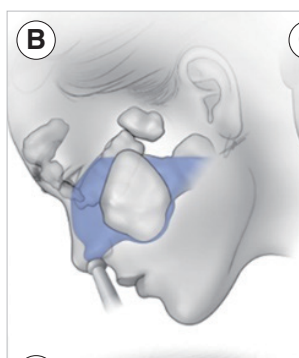
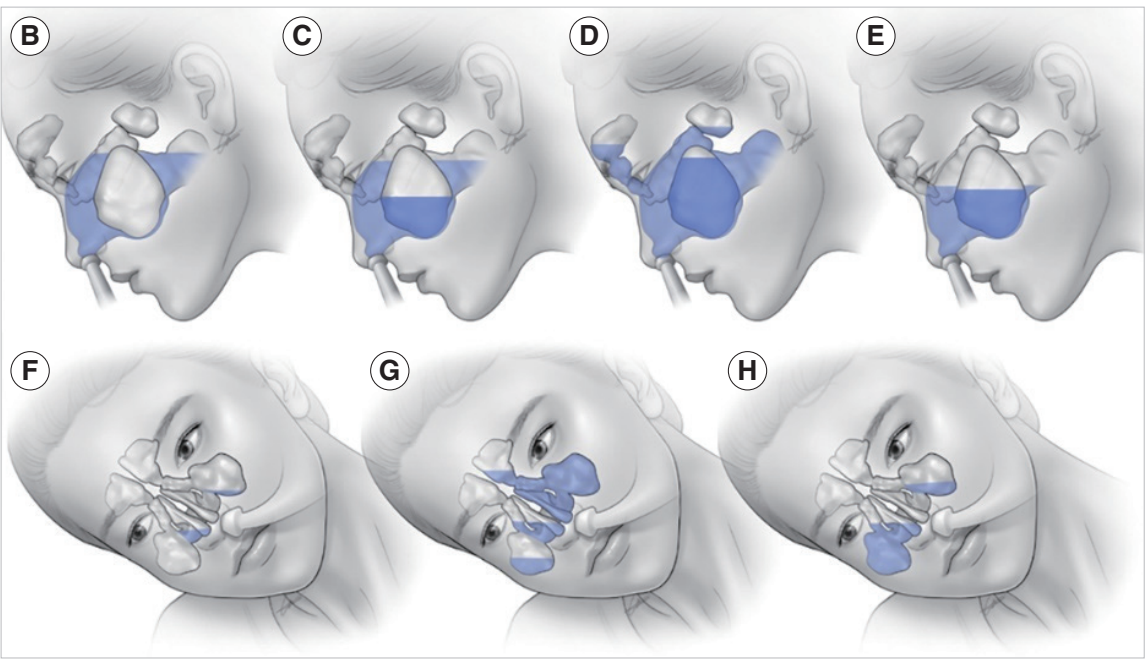

(G)

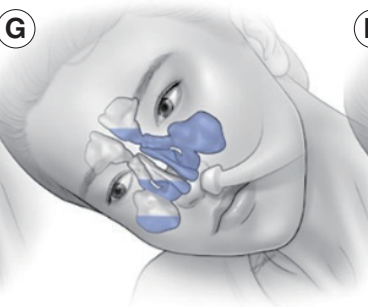

(H)

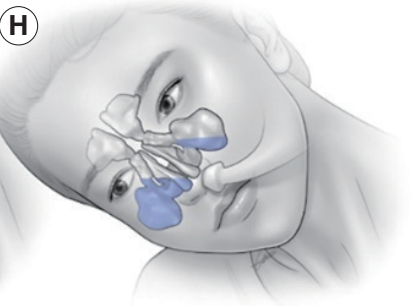

Fig. 1. Mechanism and sequence of irrigation of the nasal cavity and nose. (A) The diagram showing the location and relationship of each sinus and nasal cavity. (B-H) The irrigation fluid first hits the nasopharynx and then indirectly enters the sinus. According to cadaveric and threedimensional modeling studies, the fluid first passes through the ethmoid and nasopharynx, then the ipsilateral maxillary and sphenoid sinuses, followed by the frontal sinus and then the opposite side of the maxillary sinus.

\section{INTRODUCTION}

Rhinosinusitis is a disease with a relatively high prevalence characterized by inflammation of the nasal cavity or paranasal sinuses. Depending on the duration of symptoms, it is divided into acute or chronic, and it is classified as chronic rhinosinusitis (CRS) when symptoms last for more than 12 weeks [1]. Unlike acute rhinosinusitis, the etiology of CRS shows more complex characteristics of inflammation. It is known that approximately $30 \%$ of patients with CRS undergo surgery because they do not respond to maximal medical treatment or have refractory CRS symptoms [2-5]. Due to the refractory characteristics and complex etiology of CRS, various methods such as corticosteroids, antibiotics, antihistamines, nasal decongestants, immunomodulators, anti-in-

\section{H I G H L I G G H T S}

- The Korean Society of Otorhinolaryngology-Head and Neck Surgery and Korean Rhinologic Society developed a practice guideline for nasal irrigation to treat chronic rhinosinusitis (CRS) in adult patients.

- The committee developed 11 key action statements.

- The statements deal with the effect of nasal irrigation, the preparation of the solution, the management of the equipment, disinfection, and posture.

- The target audience of this guideline is any clinician or individual involved in the management of adult patients with CRS in any setting.

- This guideline is intended to promote more active use of nasal irrigation to treat CRS, improve treatment outcomes, and enhance the doctor-patient relationship. terleukins, other medications, and nasal irrigation have been used to manage CRS. Of these methods, nasal irrigation is expected to have anti-inflammatory effects. The effectiveness and necessity of nasal irrigation have been sufficiently verified. To avoid abuse of antibiotics, nasal irrigation is encouraged as the first-line treatment for CRS in various guidelines, and its clinical effectiveness has been demonstrated through many highly reliable studies [6,7]. In addition, during the postoperative period after endoscopic sinus surgery (ESS), sinus irrigation has been demonstrated to be an important method for promoting wound recovery in the nasal cavity and sinuses and as a method to reduce the use of unnecessary drugs.

Nasal irrigation is expected to have anti-inflammatory effects. The effectiveness and necessity of nasal irrigation have been sufficiently verified, but studies on the method of use and characteristics of irrigation liquids have been somewhat inconsistent. Despite the efficacy of irrigation, the complex structure of the sinuses and the various connections between the sinuses make it challenging to determine the cleaning process and anti-inflammatory mechanism. Recently, through three-dimensional modeling and cadaveric studies of the nasal sinuses, it has been revealed that the irrigation fluid flows mainly indirectly, as opposed to directly penetrating the sinuses. The irrigation fluid was found to flow in the following order: ethmoid sinus, nasopharynx, ipsilateral maxillary sinus, contralateral maxillary sinus, and ipsilateral frontal sinus (Fig. 1) [8-12]. Nasal saline irrigation may improve nasal mucosa function through several physiological effects, including direct cleaning of the mucus to prevent bacterial growth. Moreover, saline dilutes the mucus to promote cleaning and removal of antigens and bacterial biofilm and promotes inflammatory mediators to improve inflammation and 
mucociliary function [13]. Nasal saline irrigation in CRS after ESS has been proven to clean the nasal cavity and promote the restoration of mucosal function [14-16].

Despite the importance of nasal irrigation for the management of CRS, a nasal irrigation guideline for consistent medical practice and patient education has not been published. The target population of this guideline is patients who are 18 years or older with a clinical diagnosis of uncomplicated rhinosinusitis. We defined rhinosinusitis as symptomatic inflammation of the paranasal sinuses and nasal cavity. The guideline development group (GDG) preferred the term "rhinosinusitis" because sinusitis is accompanied by inflammation of the nasal mucosa. Therefore, the term rhinosinusitis was used in this guideline. We defined uncomplicated rhinosinusitis as cases without clinical extension of inflammation outside the paranasal sinuses and nasal cavity, such as neurologic, ophthalmologic, or soft tissue involvement.

\section{HEALTHCARE BURDEN}

CRS is a significant health problem, and the overall prevalence of symptom-based CRS has been reported to be between $6 \%$ and $28 \%$ [17-20]. The prevalence of CRS is suggested to be between $3 \%$ and $6 \%$ in those diagnosed through a combination of symptoms and tests such as endoscopy and computed tomography [21-23]. CRS has also been shown to have a number of negative socioeconomic effects. It has been reported that 18.3 million patients in the United States (US) visited hospitals with symptoms of CRS and received more than five times as many prescriptions as those with other diseases [24,25]. In 2007 alone, $\$ 8.3$ billion was spent on CRS, with more than 250,000 surgical procedures performed annually, at an average of $\$ 7,700$ each. In the United Kingdom, $£ 2,974$ was found to be spent on primary and secondary care for CRS annually [26]. The direct cost of CRS was reported to be $€ 1,501$ per year in a group of Dutch patients with CRS and nasal polyps (CRSwNP). The highest direct cost was incurred in patients who experienced recurrence even after surgery $[27,28]$. As rhinosinusitis can occur in younger patients, higher absenteeism due to the disease has been reported than is the case for a number of other diseases. Rhinosinusitis has very high costs for workers in the US. On average, there are 1 to 2 days of missed working days per worker per year, and the total indirect costs for the management of CRS are reported to exceed $\$ 20$ billion per year [29-31]. Additionally, the overall productivity loss for patients with refractory CRS is reported to be $\$ 10,077$ per patient annually [32]. The significant adverse effects of CRS have been reported to negatively affect the quality of life in general healthcare questionnaires [33-36] and rhinological symptom questionnaires $[37,38]$. In patients with CRS, quality of life scores in terms of chronic pain and adverse social effects were reported to be worse than those for angina, back pain, and congestive heart failure [39-42].

\section{GUIDELINE SCOPE AND PURPOSE}

This guideline aims to provide quality improvement opportunities in the application of nasal irrigation and to create concrete and actionable recommendations to implement these opportunities in clinical practice. This guideline aims to improve the effectiveness of nasal irrigation, promote appropriate drug use, and promote effective disease management by presenting a general nasal irrigation method and detailing the appropriate management of irrigation fluid and devices based on the findings of robust studies. The guidelines are intended for all clinicians who are likely to manage rhinosinusitis and recommend nasal irrigation to patients. This guideline aims to increase the efficiency of nasal irrigation and can be applied in any setting for adults with rhinosinusitis who have undergone ESS. However, this guideline is not aimed at patients with rhinosinusitis complications or those under the age of 18 years. The GDG believes that the effectiveness of nasal irrigation will not differ significantly between children/adolescents and adults with CRS. However, in pediatric patients, it is thought that the degree of adaptation in response to various tonicities and the response to additional drugs in the irrigation solution may differ, and we did not find sufficient evidence regarding this possibility. Accordingly, since the papers we searched and cited in establishing this guideline were for adults, pediatric patients were excluded from the application. In addition, these guidelines do not apply to diseases such as allergic rhinitis, eosinophilic nonallergic rhinitis, vasomotor rhinitis, invasive fungal rhinosinusitis, and allergic fungal rhinosinusitis.

\section{METHODS}

\section{Organization of the committee}

The Task Force Chairman (YGJ), who was appointed by the Korean Society of Otorhinolaryngology-Head and Neck Surgery (KORL-HNS) President with the approval of the committee, selected the members of the GDG. The GDG consisted of 11 specialists in rhinology from South Korea. The Korean Rhinologic Society recommended a review member (JHM), and the member supervised the academic content of this paper and participated in the manuscript as an author. The GDG had complete editorial independence from the KORL-HNS. In developing this consensus-based clinical practice guideline, the GDG followed the Clinical Practice Guideline Development Manual,Third Edition with the aim of creating actionable statements [43]. The first meeting was held in July 2020, and a total of 20 conference calls or meetings were held. In a series of conference calls and meetings, the GDG defined the scope and objectives of the proposed guideline and selected key questions. The GDG determined that the development of a consensus-based clinical practice guideline for nasal irrigation would be most beneficial for 
clinicians who manage patients with CRS. After deciding on the scope and objectives, the development of this consensus-based clinical practice guideline took place over 3 months, and all the key questions and the corresponding action statements were created based on supporting evidence, balancing the benefits and potential harm of each. The recommendations contained in this consensus-based clinical practice guideline were developed based on the selected best literature published through December 2020 depending on the opinion of the GDG members. If we could not find enough data, we used a combination of clinical experience and expert consensus. When any disagreements occurred, a third author created the actionable statements as necessary. The clinical practice guideline developed also underwent extensive external peer review. Finally, comments were compiled and reviewed by the GDG members. The final modified version of the clinical practice guideline was distributed and approved by the board of directors of the KORL-HNS. A total of 11 guideline recommendations regarding nasal irrigation are included, along with corresponding action statements and profiles, which are reproduced in the results section.

\section{Literature search}

After establishing the key questions, the GDG reached a consensus about the keywords to use in the literature search. This literature search was performed using a validated filter strategy to identify clinical practice guidelines, systematic reviews, randomized controlled trials (RCTs), observational studies, case series, or expert opinions. English-language searches were performed in multiple databases, including the Cochrane Library, Embase, and PubMed. Additionally, targeted searches for lowerlevel evidence were performed by GDG members to address any gaps identified. During the literature search, we applied the following limits: search fields (title, abstract, keywords), species (adult humans), and target disease (CRS, with or without polyps). Specifically, we excluded studies in which the majority of patients had cystic fibrosis, allergic fungal sinusitis/eosinophilic fungal/mucinous rhinosinusitis, aspirin-exacerbated respiratory disease, or a history of surgery for nasal polyps within 6 weeks of entry into the study. However, to obtain sufficient literature, the search was not limited by publication year. At least two review members of GDG independently screened all titles and abstracts of the studies obtained from the database searches to identify potentially relevant studies and exclude those deemed to be irrelevant. After removing duplicates and irrelevant references, the GDG members performed a full-text review to determine the papers for final inclusion.

\section{Classification of evidence-based statements}

Clinical practice guidelines are intended to reduce inappropriate variations in clinical care, minimize harm, promote cost-effective practice, and produce optimal health outcomes for patients. Thus, an evidence-based approach to guideline development requires
Table 1. Level of evidence

\begin{tabular}{ll}
\hline Term & Definition \\
\hline High-quality evidence & $\begin{array}{r}\text { RCTs without important limitations or overwhelming } \\
\text { evidence from observational studies }\end{array}$ \\
$\begin{array}{cc}\begin{array}{c}\text { Medium-quality } \\
\text { evidence }\end{array} & \text { RCTs with important limitations or strong evidence } \\
\text { from observational studies }\end{array}$ \\
$\begin{array}{cc}\text { Low-quality evidence } & \text { Observational studies/case studies/expert opinion }\end{array}$
\end{tabular}

$\mathrm{RCT}$, randomized controlled trial.

that the evidence supporting a policy be identified, appraised, and summarized and that an explicit link between the evidence and statements be defined. The recommended actions are stated along with the specific circumstances under which to perform them, linked to the supporting evidence. The potential benefits and risks associated with the recommendations are also described. Therefore, evidence-based statements should reflect both the quality of evidence and the expected balance between the benefits and harm for patients. Similar to previous guidelines, the GDG evaluated the evidence levels of the literature as highquality, medium-quality, or low-quality evidence (Table 1). In this framework, RCTs are designated as high-quality evidence and case series or expert opinions as low-quality evidence based on the probability of bias. The GDG developed evidence-based statements that reflected both the quality of evidence and the balance between potential harm and benefits. The definitions of evidence-based statements are listed in Tables 2 and 3 [44]. Table 2 was adapted to include only treatment recommendations from the Oxford Centre for Evidence-Based Medicine. This clinical practice guideline is based on the best available scientific evidence for the key questions as determined by the GDG. This means that our clinical practice guideline is not intended to replace the professional judgment of clinicians, but should help to inform clinical decision-making in particular clinical circumstances. The GDG proposed that action statements would be strongly recommended when less frequent variation in clinical practice may be expected (Table 3). By contrast, those deemed to be an "option" could be selected depending on the clinical situation. Therefore, clinicians should always act and decide in a way that they believe will best serve their patients' interests and needs, regardless of our recommendations in this guideline. The primary goal of the GDG was to establish a clinical practice guideline through a transparent process and to document this process.

\section{Description of action statements}

Here, we will clearly describe the processes that led to the profile of each consensus-based action statement. Each consensusbased action statement is expressed as follows: an action statement in bold, followed by the strength of the recommendation in italics. Each action statement is also followed by the "action statement profile" with quality improvement opportunities, level of confidence in the evidence, aggregate evidence quality, benefits, risk/harm/cost, benefit-harm assessment, value judg- 
Table 2. Aggregate grades of evidence by question type

\begin{tabular}{lccl}
\hline Grade & OCEBM Level & Treatment & Harm \\
\hline A & 1 & Systematic review of randomized trials & $\begin{array}{c}\text { Systematic review of randomized trials, nested case-control studies, or } \\
\text { observational studies with dramatic effect }\end{array}$ \\
B & 2 & $\begin{array}{c}\text { Randomized trials or observational studies with } \\
\text { dramatic effects or highly consistent evidence }\end{array}$ & $\begin{array}{c}\text { Randomized trials or observational studies with dramatic effects or highly } \\
\text { consistent evidence }\end{array}$ \\
C & $3-4$ & $\begin{array}{c}\text { Nonrandomized or historically controlled studies, } \\
\text { including case-control and observational studies }\end{array}$ & $\begin{array}{c}\text { Nonrandomized controlled cohort or follow-up study (post-marketing } \\
\text { surveillance) with sufficient numbers to rule out a common harm, } \\
\text { case-series, case-control, or historically controlled studies }\end{array}$ \\
X & 5 & Case reports, mechanism-based reasoning, or reasoning from first principles \\
\hline
\end{tabular}

OCEBM, Oxford Centre for Evidence-Based Medicine; NA, not applicable.

Table 3. Guideline definitions for evidence-based statements

\begin{tabular}{|c|c|c|}
\hline Statement & Definition & Implied obligation \\
\hline Strong recommendation & $\begin{array}{l}\text { A strong recommendation means that the benefits of the recommended } \\
\text { approach clearly exceed the harms (or that the harms clearly exceed the } \\
\text { benefits in the case of a strong negative recommendation) and that the } \\
\text { quality of the supporting evidence is excellent (grade A or B). In some } \\
\text { clearly identified circumstances, strong recommendations may be made } \\
\text { on the basis of lesser evidence when high-quality evidence is impossible } \\
\text { to obtain and the anticipated benefits strongly outweigh the harms. }\end{array}$ & $\begin{array}{l}\text { Clinicians should follow a strong recommendation } \\
\text { unless a clear and compelling rationale for an } \\
\text { alternative approach is present. }\end{array}$ \\
\hline Recommendation & $\begin{array}{l}\text { A recommendation means that the benefits exceed the harms (or that the } \\
\text { harms exceed the benefits in the case of a negative recommendation), } \\
\text { but the quality of evidence is not as strong (grade B or } \mathrm{C} \text { ). In some clearly } \\
\text { identified circumstances, recommendations may be made on the basis of } \\
\text { lesser evidence when high-quality evidence is impossible to obtain and } \\
\text { the anticipated benefits outweigh the harms. }\end{array}$ & $\begin{array}{l}\text { Clinicians should also generally follow a } \\
\text { recommendation but should remain alert to } \\
\text { new information and sensitive to patient } \\
\text { preferences. }\end{array}$ \\
\hline Option & $\begin{array}{l}\text { An option means that either the quality of evidence that exists is suspect } \\
\text { (grade D) or those well-done studies (grade A, B, or C) show little clear } \\
\text { advantage to one approach versus another. }\end{array}$ & $\begin{array}{l}\text { Clinicians should be flexible in their decision- } \\
\text { making regarding appropriate practice, } \\
\text { although they may set bounds on alternatives. } \\
\text { Patient preference should have a substantial } \\
\text { influencing role. }\end{array}$ \\
\hline
\end{tabular}

ments, intentional vagueness, the role of patient preferences, exclusion, policy level, and differences of opinion. Several paragraphs subsequently discuss the evidence supporting this statement. In the action statement descriptions, we have shared our decision-making by referring to the risks and benefits of treatment and providing information on patient preferences that could enhance the doctor-patient relationship. An overview of each consensus-based statement covered in this guideline is presented in Table 4.

\section{KEY ACTION STATEMENTS}

Statement 1. Nasal saline irrigation: clinicians should recommend nasal saline irrigation to patients with CRS or those who have undergone ESS. Strong recommendation based on multiple systematic reviews and RCTs, as well as a preponderance of benefits over harm.

\section{Action statement profile: 1}

- Quality improvement opportunity: To improve the utilization of nasal irrigation for the treatment of patients with CRS. Nasal irrigation improves the patient's symptoms safely and is associated with a low financial burden. It also provides a route through which various drugs can be effectively delivered to the nasal cavity and sinuses.

- Level of confidence in evidence: High.

- Aggregate evidence quality: Grade A, based on systematic reviews and multiple RCTs.

- Benefits: Nasal irrigation washes away inflammatory mediators, crust, and dirty mucus; disrupts biofilms; improves mucociliary transport; decreases mucosal edema; and hydrates the mucus sol layer.

- Risk, harm, and cost: There is a low probability of local irritation, a nasal burning sensation, nausea, itching, pain, otalgia, and epistaxis. It is very inexpensive to perform a nose wash twice a day; thus, the financial burden is limited.

- Benefit-harm assessment: Preponderance of benefits over harm. 
Table 4. Summary of evidence-based statements

\begin{tabular}{|c|c|c|}
\hline Statement & Action & Strength \\
\hline 1. Nasal saline irrigation & $\begin{array}{l}\text { Clinicians should recommend nasal saline irrigation to patients with chronic sinusitis or those who have } \\
\text { undergone endoscopic sinus surgery. }\end{array}$ & $\begin{array}{l}\text { Strong } \\
\text { recommendation }\end{array}$ \\
\hline 2. Saline tonicity & $\begin{array}{l}\text { Clinicians may recommend using isotonic saline as a nasal irrigation solution for patients considering cost, } \\
\text { convenience, and safety. However, it is unclear whether there is a clear difference in the therapeutic } \\
\text { effect of hypertonic and isotonic saline solutions. }\end{array}$ & Option \\
\hline 3. Saline temperature & $\begin{array}{l}\text { Clinicians may recommend using room-temperature saline (around } 20^{\circ} \mathrm{C} \text { ) as a nasal irrigation solution for } \\
\text { patients considering effectiveness and convenience. If the patient prefers, then it is also completely } \\
\text { acceptable to use a saline solution heated to } 40^{\circ} \mathrm{C} \text {. However, it is not recommended to immediately use } \\
\text { a solution that has been refrigerated or to use a hot solution that exceeds } 40^{\circ} \mathrm{C} \text { for safety reasons. }\end{array}$ & Option \\
\hline 4. Steroid solution & $\begin{array}{l}\text { Clinicians may recommend nasal irrigation with solutions containing steroids to patients with chronic } \\
\text { rhinosinusitis who have undergone endoscopic sinus surgery. }\end{array}$ & Option \\
\hline 5. Antibiotic solution & $\begin{array}{l}\text { Clinicians should not routinely recommend nasal irrigation with solutions containing antibiotics for the } \\
\text { management of patients with chronic rhinosinusitis or those who have undergone endoscopic sinus } \\
\text { surgery. }\end{array}$ & $\begin{array}{c}\text { Recommendation } \\
\text { against }\end{array}$ \\
\hline 6. Antifungal solution & $\begin{array}{l}\text { Clinicians should not routinely recommend nasal irrigation with solutions containing antifungal agents for } \\
\text { the management of patients with chronic rhinosinusitis or those who have undergone endoscopic sinus } \\
\text { surgery. }\end{array}$ & $\begin{array}{l}\text { Recommendation } \\
\text { against }\end{array}$ \\
\hline $\begin{array}{l}\text { 7a. Miscellaneous } \\
\text { solution-hyaluronate }\end{array}$ & $\begin{array}{l}\text { Clinicians may recommend nasal irrigation with solutions containing sodium hyaluronate to patients with } \\
\text { chronic rhinosinusitis. }\end{array}$ & Option \\
\hline $\begin{array}{l}\text { 7b. Miscellaneous } \\
\text { solution-xylitol }\end{array}$ & $\begin{array}{l}\text { Clinicians may recommend nasal irrigation with solutions containing xylitol to patients post-endoscopic } \\
\text { sinus surgery. }\end{array}$ & Option \\
\hline $\begin{array}{l}\text { 7c. Miscellaneous } \\
\text { solution-honey }\end{array}$ & $\begin{array}{l}\text { Clinicians should not routinely recommend nasal irrigation with solutions containing honey for the } \\
\text { management of patients with chronic rhinosinusitis or those who have undergone endoscopic sinus } \\
\text { surgery. }\end{array}$ & $\begin{array}{c}\text { Recommendation } \\
\text { against }\end{array}$ \\
\hline $\begin{array}{l}\text { 8. Irrigation solution } \\
\text { preparation }\end{array}$ & $\begin{array}{l}\text { Clinicians should recommend an appropriate irrigation fluid preparation method for patients with chronic } \\
\text { rhinosinusitis or those who have undergone endoscopic sinus surgery. For irrigation fluid, bottled or } \\
\text { distilled water should preferably be used. If tap water is used, boil it for at least } 5 \text { minutes and cool } \\
\text { before use or expose it to ultraviolet light for at least } 45 \text { seconds. }\end{array}$ & Recommendation \\
\hline 9. Equipment & $\begin{array}{l}\text { Clinicians should recommend nasal irrigation performed by high-volume with low-or high-pressure } \\
\text { delivery rather than low-volume with low- or high-pressure delivery in patients with chronic rhinosinusitis. }\end{array}$ & Recommendation \\
\hline 10. Disinfection & $\begin{array}{l}\text { Clinicians should recommend the following techniques for appropriate irrigation equipment care to } \\
\text { patients with chronic rhinosinusitis or those who have undergone endoscopic sinus surgery. Irrigation } \\
\text { equipment (according to the equipment material and manufacturer's recommendations, if possible) } \\
\text { should be boiled (for more than } 2 \text { minutes) or microwaved for } 1 \text { minute and } 30 \text { seconds regularly before } \\
\text { and after use. }\end{array}$ & Recommendation \\
\hline 11. Posture & $\begin{array}{l}\text { Clinicians may recommend the head down-and-forward position as being better for high-volume nasal } \\
\text { irrigation, whereas the nose-to-ceiling position is more effective at delivering low-volume nasal irrigation. }\end{array}$ & Option \\
\hline
\end{tabular}

- Value judgment: None.

- Intentional vagueness: There is still a lack of clear high-level evidence on how to irrigate the sinuses, the type of equipment to use, the tonicity of the solution, the temperature and amount of the solution, the frequency and duration of irrigation, as well as the best position to perform the irrigation. These are described in the following statements.

- Role of patient preferences: Low.

- Exclusions: Cases of active nose bleeding or high risk of aspiration.

- Policy level: Strong recommendation.

- Differences of opinion: None.

\section{Supporting text}

Nasal saline irrigation plays a crucial role in the treatment of CRS. Nasal saline irrigation for patients with chronic sinusitis or after ESS was recommended in the Cochrane Review published in 2016 [45], the European Position Paper on Rhinosinusitis and Nasal Polyps (EPOS) guideline published in 2020 [7], and the International Forum of Allergy and Rhinology Consensus Statement in 2021 [46]. Nasal irrigation can be actively recommended for patients with CRS because it does not pose a medical risk or financial burden to patients. Nasal irrigation is known to improve CRS by thinning any mucus that is present, mechanically removing the mucus and crust, improving mucociliary transport, decreasing mucosal edema, reducing the surface antigen load, disrupting biofilms, washing out inflammatory mediators, and hydrating the sol layer [46-48]. The side effects of nasal irrigation are generally mild or uncommon, and nasal pain and bleeding may occur. In particular, symptoms such as nasal pain or irritation are related to the use of hypertonic solutions. Nasal irrigation improves symptom scores and discharge after ESS in pa- 
tients with CRS $[49,50]$.

Statement 2. Saline tonicity: clinicians may recommend using isotonic saline as a nasal irrigation solution for patients considering cost, convenience, and safety. However, it is unclear whether there is a clear difference in the therapeutic effect of hypertonic and isotonic saline solutions. Option based on one systematic review and seven RCTs with isotonic and hypertonic saline balances. However, isotonic saline is recommended in terms of cost, convenience, and safety.

\section{Action statement profile: 2}

- Quality improvement opportunity:To provide physicians with information on the therapeutic and side effects of isotonic and hypertonic saline solutions. Although isotonic saline is widely used for nasal irrigation, it is not easy to determine whether there is a clear difference in the therapeutic effect depending on the tonicity. Therefore, hypertonic saline could also be used for nasal irrigation.

- Level of confidence in evidence: Medium.

- Aggregate evidence quality: Grade B based on multiple RCTs.

- Benefits: Isotonic saline-related products for nasal irrigation are widely sold, and patients can easily obtain them compared to hypertonic saline.

- Risk, harm, and cost: Patient discomfort occurred more frequently in nasal irrigation with hypertonic saline. Unlike isotonic saline, hypertonic saline and Ringer's lactate solution are often not commercially available for nasal irrigation in most countries, including South Korea. Thus, physicians are less likely to recommend the solution to patients.

- Benefit-harm assessment: Preponderance of benefits over harm.

- Value judgment: The GDG judged that in terms of convenience for patients and irritation symptoms, isotonic solutions were preferable to hypertonic solutions. Moreover, there were no significant differences in the therapeutic effect.

- Intentional vagueness: It was not specified whether readymade isotonic saline or solutions made using commercially available sodium chloride powder were used.

- Role of patient preferences: Moderate.

- Exclusion: None.

- Policy level: Option.

- Differences of opinion: None.

\section{Supporting text}

In vitro studies have reported that hypertonic saline reduces nasal mucosal edema and increases the ciliary beat frequency [51]. However, in in vivo studies of patients with CRS, the difference in the improvement of patient symptoms according to tonicity is unclear. Three RCTs reported that isotonic saline was more helpful in improving the symptoms of patients with CRS [5254], and two studies reported no differences between isotonic and hypertonic saline [51,55]. On the contrary, two RCTs and one systematic review showed that hypertonic saline helped improve symptoms compared to isotonic saline [56-58]. As for the side effects of nasal irrigation, some studies have reported that hypertonic saline may cause a burning sensation, increased nasal discharge, and pain, and the relative risk ratio compared to isotonic saline was 2.38 (95\% confidence interval, 1.05-5.40) [59]. In one study, Ringer's lactate solution showed a significantly superior effect on symptom improvement after ESS compared to saline [60]. However, there is insufficient evidence to recommend Ringer's lactate solution. Several different isotonic saline preparation kits are available in the market, and patients can easily purchase and use them. Thus, these can be recommended to patients. However, in South Korea, there are few commercially available hypertonic saline solutions or no Ringer's lactate solution preparation kits. Therefore, considering patients' convenience, clinicians should be cautious about recommending using a hypertonic or Ringer's lactate solution.

Statement 3. Saline temperature: clinicians may recommend using room-temperature saline (around $20^{\circ} \mathrm{C}$ ) as a nasal irrigation solution for patients considering effectiveness and convenience. If the patient prefers, then it is also completely acceptable to use a saline solution heated to $40^{\circ} \mathrm{C}$. However, it is not recommended to immediately use a solution that has been refrigerated or to use a hot solution that exceeds $40^{\circ} \mathrm{C}$ for safety reasons. Option based on multiple RCTs, one case study, and multiple in vitro studies with room temperature and heated (up to $40^{\circ} \mathrm{C}$ ) saline.

\section{Action statement profile: 3}

- Quality improvement opportunity: To maximize the effect of irrigation, it is recommended that patients do not store the irrigation solution in a refrigerator or heat the washing solution unnecessarily. Moreover, an appropriate solution temperature should be recommended.

- Level of confidence in evidence: Medium.

- Aggregate evidence quality: Grade B based on RCTs and in vitro studies.

- Benefits: Maintaining the solution at room temperature and using it immediately is convenient and effective for patients.

- Risk, harm, and cost: Exostoses have been reported after repeat irrigation with very low-temperature saline. A temperature higher than $40^{\circ} \mathrm{C}$ may cause patient discomfort and decreased mucociliary transport.

- Benefit-harm assessment: Preponderance of benefits over harm.

- Value judgment: Room temperature may vary depending on 
the situation, but it was judged to be $18^{\circ} \mathrm{C}$ or higher based on the literature.

- Intentional vagueness: None.

- Role of patient preferences: Moderate.

- Exclusion: None.

- Policy level: Option.

- Differences of opinion: None.

\section{Supporting text}

In vitro studies have reported that at temperatures below $20^{\circ} \mathrm{C}$ or above $40^{\circ} \mathrm{C}$, the ciliary beat frequency decreases, and when it reaches $5^{\circ} \mathrm{C}$ or $50^{\circ} \mathrm{C}$, the cilia stop moving [61,62]. Two RCTs analyzed the saccharine transit time (STT) according to the nasal irrigation solution temperature [63,64]. A study evaluating the STT and patient symptoms reported that there was no difference in patient symptoms and the STT between room-temperature and heated solutions (up to $40^{\circ} \mathrm{C}$ ) [63]. In other studies that measured only the STT, the STT decreased significantly more when a $37^{\circ} \mathrm{C}$ solution was used than when a $20^{\circ} \mathrm{C}$ solution was used [64]. In some cases, patients may store the solution in a refrigerator to prevent bacterial growth. However, longterm irrigation with a low-temperature solution may induce exostoses in the bone tissue in the nasal cavity [65], and the use of excessively cold solutions is not recommended for safety and effectiveness.

Statement 4. Steroid solution: clinicians may recommend nasal irrigation with solutions containing steroids to CRS patients who have undergone ESS. Option based on RCTs and a preponderance of benefits over harm.

\section{Action statement profile: 4}

- Quality improvement opportunity: To promote inflammation reduction and wound healing in patients undergoing ESS.

- Level of confidence in evidence: Medium.

- Aggregate evidence quality: Grade B, based on RCTs.

- Benefits: Steroid nasal irrigation improves postoperative nasal symptoms and inflammation.

- Risk, harm, and cost: No serious complications have been reported, including hypothalamic-pituitary-adrenal (HPA) axis suppression, increased intraocular pressure, and posterior subcapsular cataracts. The complications of steroid nasal irrigation are relatively minor and similar to those caused by general saline nasal irrigation. The cost is moderate.

- Benefit-harm assessment: Preponderance of benefits over harm.

- Value judgments: None.

- Intentional vagueness: The effect of steroid nasal irrigation may vary depending on the type and dose of the steroid, as well as irrigation frequency.
- Role of patient preferences: None.

- Exclusions: None.

- Policy level: Option.

- Differences of opinion: None.

\section{Supporting text}

Primary CRS is characterized by prolonged inflammation of the nasal cavity and paranasal sinuses $[7,46,66]$. Thus, nasal irrigation with a steroid solution is theoretically predicted to help reduce symptoms and inflammation in CRS, especially in the postoperative state, in addition to the effects of saline irrigation described above. A double-blind placebo-controlled study investigated the effect of steroid nasal irrigation versus steroid nasal spray on patients' symptoms, endoscopic views, and radiologic findings after ESS [67]. The study outcomes showed that steroid nasal irrigation improved patients' symptoms and endoscopic and radiologic scores compared to steroid nasal spray [67]. Steroid nasal irrigation was found to be more effective than no irrigation for postoperative management in patients with CRS [68]. In clinical studies that compared the effects of steroid nasal irrigation and saline nasal irrigation in patients with CRS, both were found to be significantly effective in postoperative care [69-72]. In summary, steroid nasal irrigation may be similar to or more effective than saline nasal irrigation. Some studies have evaluated the safety of steroid nasal irrigation [66,73-77]. Consequently, steroid nasal irrigation is a relatively safe therapeutic method that does not increase the risk of serious complications, including systemic HPA axis suppression, intraocular pressure elevation, and subcapsular cataracts. Recent clinical guidelines and review articles have suggested that steroid nasal irrigation is an option for patients with CRS, particularly post-ESS $[7,46,66$, 78-80].

Statement 5. Antibiotic solution: clinicians should not routinely recommend nasal irrigation with solutions containing antibiotics for the management of patients with CRS or those who have undergone ESS. Recommendation against, based on RCTs and a preponderance of harm over benefits.

\section{Action statement profile: 5}

- Quality improvement opportunity: It is recommended not to add an antibiotic nasal solution to the saline nasal irrigation fluid.

- Level of confidence in evidence: Medium.

- Aggregate evidence quality: Grade B, based on RCTs.

- Benefits:There is no clear benefit to adding an antibiotic nasal solution to the irrigation fluid. Not adding an antibiotic nasal solution helps to avoid unnecessary adverse events and changes management from an ineffective therapy to a beneficial therapy (opportunity cost). 
- Risk, harm, and cost: Some complications can be caused by general saline nasal irrigation, including nasal obstruction, irritation, and bleeding. In addition, there is a theoretical possibility that local antibiotics can be absorbed systemically and that bacterial resistance could develop. The cost is moderate to high, depending on the type of antibiotic and dosage used.

- Benefit-harm assessment: Preponderance of relative harm over benefits. The benefits cannot outweigh the harm, including the risk and cost.

- Value judgments: None.

- Intentional vagueness: None.

- Role of patient preferences: None.

- Exclusions: None.

- Policy level: Recommendation against.

- Differences of opinion: None.

\section{Supporting text}

There is no evidence that nasal irrigation with antibiotics is more effective than nasal irrigation without antibiotics to treat CRS or after ESS. Recent clinical guidelines and review articles have recommended against the use of antibiotic nasal irrigation to manage CRS or after ESS $[7,46,78,79]$. Therefore, antibiotic nasal irrigation should not be routinely used as first-line therapy to manage CRS or in patients after ESS. However, a few studies have shown that nasal irrigation with antibiotics such as mupirocin is effective in certain surgically recalcitrant patients with CRS [81-83]. Therefore, in these cases only, antibiotic nasal irrigation may be considered as an alternative therapeutic option if there is no response to other treatments.

Statement 6. Antifungal solution: clinicians should not routinely recommend nasal irrigation with solutions containing antifungal agents for the management of patients with CRS or those who have undergone ESS. Recommendation against based on RCTs and a preponderance of harm over benefits.

\section{Action statement profile: 6}

- Quality improvement opportunity: It is recommended not to add an antifungal nasal solution to saline nasal irrigation fluid.

- Level of confidence in evidence: High.

- Aggregate evidence quality: Grade A, based on RCTs.

- Benefits: There is no clear benefit to adding an antifungal nasal solution to irrigation fluid. Not adding an antifungal nasal solution helps to avoid unnecessary adverse events and changes management from an ineffective therapy to a beneficial therapy (opportunity cost).

- Risk, harm, and cost: Local irritation is a common adverse effect. The other complications of antifungal nasal irrigation are similar to those associated with saline nasal irrigation. The cost is moderate.
- Benefit-harm assessment: Preponderance of harm over benefits. The benefits cannot outweigh the harm, including risk and cost.

- Value judgments: None.

- Intentional vagueness: None.

- Role of patient preferences: None.

- Exclusions: None.

- Policy level: Recommendation against.

- Differences of opinion: None.

\section{Supporting text}

No evidence was found that nasal irrigation with antifungal agents is more effective than nasal irrigation without antifungal agents for treating patients with CRS or those who have undergone ESS [84-88]. A randomized, placebo-controlled, doubleblind study evaluated the effect of amphotericin B nasal irrigation versus saline nasal irrigation for post-ESS care [87]. This study demonstrated no significant differences in symptoms, endoscopic findings, STT results, olfactory function test results, and bacterial culture rates between antifungal nasal irrigation and saline nasal irrigation for post-ESS care [87]. Recent studies, including clinical guidelines, review articles, and meta-analyses, highlight that clinicians should recommend against antifungal nasal irrigation to manage CRS or post-ESS $[7,46,78,79,89]$.

Statement 7a. Miscellaneous solution-hyaluronate: clinicians may recommend nasal irrigation with solutions containing sodium hyaluronate to patients with CRS. Option based on RCTs and a preponderance of benefits over harm.

\section{Action statement profile: $7 a$}

- Quality improvement opportunity: To improve symptomatic relief in patients with CRS, and to reduce inflammation and promote wound healing in patients with CRS undergoing ESS.

- Level of confidence in evidence: Medium.

- Aggregate evidence quality: Grade B, based on RCTs.

- Benefits: Improvement of symptoms in patients with CRS undergoing medical treatment and improvement of symptoms and better wound recovery in patients undergoing ESS.

- Risk, harm, and cost:There are no known complications other than those that can be caused by general nasal irrigation, but there may be a risk of infection in the self-manufacturing process. The cost is moderate.

- Benefit-harm assessment: Preponderance of benefits over harm.

- Value judgments: None.

- Intentional vagueness:There were a relatively large number of controlled trials found, but all of the trials were conducted in one country, and in some studies, the control group was not clear. Therefore, the GDG, considering the complications of 
general nasal irrigation and the stability of hyaluronate, concluded that the benefits outweigh any harm, but the policy level was set as an "option."

- Role of patient preferences: None.

- Exclusions: None.

- Policy level: Option.

- Differences of opinion: None.

Statement 7b. Miscellaneous solution-xylitol: clinicians may recommend nasal irrigation with solutions containing xylitol to patients post-ESS. Option based on RCTs with a preponderance of benefits over harm.

\section{Action statement profile: $7 \mathrm{~b}$}

- Quality improvement opportunity: To reduce inflammation and promote wound healing in patients undergoing ESS.

- Level of confidence in evidence: Medium.

- Aggregate evidence quality: Grade B, based on RCTs.

- Benefits: Improvement of postoperative nasal symptoms and inflammation.

- Risk, harm, and cost: There are no known complications other than those that can be caused by general nasal irrigation, but there may be a risk of infection in the self-manufacturing process. The cost is moderate.

- Benefit-harm assessment: Preponderance of benefits over harm.

- Value judgments: None.

- Intentional vagueness: There have been a small number of well-designed studies. Therefore, the GDG, considering the complications of general nasal irrigation and stability of xylitol, considered that while the benefits outweigh any harm, the policy level would be set to an "option."

- Role of patient preferences: None.

- Exclusions: None.

- Policy level: Option.

- Differences of opinion: None.

Statement 7c. Miscellaneous solution-honey: clinicians should not routinely recommend nasal irrigation with solutions containing honey for the management of patients with CRS or those who have undergone ESS. Recommendation against, based on RCTs with an unclear balance between benefits and harm.

\section{Action statement profile: 7c}

- Quality improvement opportunity: It is recommended not to add honey to nasal saline irrigation fluid.

- Level of confidence in evidence: Medium.
- Aggregate evidence quality: Grade B, based on RCTs.

- Benefits: There is no clear benefit of adding honey to irrigation fluid. Not adding honey helps to avoid unnecessary adverse events and changes management from an ineffective therapy to a beneficial therapy (opportunity cost).

- Risk, harm, and cost: The complications of nasal irrigation with honey are similar to those associated with saline nasal irrigation. Patients may be allergic to honey. The cost is high.

- Benefit-harm assessment: Preponderance of benefits over harm (for not treating).

- Value judgments: None.

- Intentional vagueness: In all of the studies that were investigated, no benefits were reported from adding honey to the irrigation fluid. In addition, there were no reports of complications that could result from this addition. However, GDG decided not to recommend its use in consideration of the risks of allergic reaction or infection associated with honey.

- Role of patient preferences: None.

- Exclusions: None.

- Policy level: Recommendation against.

- Differences of opinion: None.

\section{Supporting text}

The purpose of this statement is to convey the availability of solutions or additives that have been studied, except for the major nasal irrigation fluids with unique characteristics and additives. According to the literature, in addition to the main nasal irrigation fluid, various studies have been conducted on solutions such as sodium hyaluronate, xylitol, honey, thermal water (sulfurous, salty, bromic, iodic), antiseptic fluid, dexpanthenol, and xyloglucan. Among these, a graded recommendation was developed for sodium hyaluronate, xylitol, and honey, as these are used and studied more frequently. Seven RCTs were conducted on nasal irrigation with sodium hyaluronate additives [90-96]. Of these, five studies were conducted in the postoperative period, and two studies were performed on patients with CRSwNP and CRS without nasal polyps (CRSsNP), respectively. Most of the studies applied the solution in the form of nebulization rather than irrigation. In four studies that used nebulization during the postoperative period, better scores in the Short Form-36 and Sinonasal Outcome Test (SNOT)-22 questionnaires were reported, along with less exudate, crust, and edema in the endoscopic findings of the group in which sodium hyaluronate was applied [90-93]. In a study that applied nasal irrigation with sodium hyaluronate in CRSsNP patients in the postoperative period, patients' symptoms and the endoscopic findings showed better results over a period of fewer than 3 weeks. However, no statistically significant difference was observed between those who received nasal irrigation with and without sodium hyaluronate at 6 weeks [94]. In a study in which sodium hyaluronate nebulizing was applied in addition to an intranasal steroid spray in patients with CRSwNP, the applied group showed better results in several questionnaires 
and radiographic findings [95]. In patients with CRSsNP, the questionnaire results, and endoscopic findings were better when nasal irrigation was performed by adding sodium hyaluronate in addition to medication [96]. In all studies, no significant complications were reported compared to the control group. Based on the hyaluronate irrigation studies reported so far, the GDG had several discussions on the policy level that should be recommended. Although there were a relatively large number of control trials, all trials were conducted in one country, and in some studies, the control group was not clear. Therefore, considering the complications of general nasal irrigation, the stability of hyaluronate, and the judgment that the benefits outweigh any harm, the policy level was set to an "option." There were three RCTs related to saline irrigation with xylitol [97-99]. All studies were conducted in the postoperative period, and in two studies, the administration of $<240 \mathrm{~mL}$ of water containing $12 \mathrm{~g}$ of xylitol once daily for 30 days was applied. The postoperative symptom scores were better in the group in which xylitol was applied $[97,98]$. One study also showed better nitric oxide production and induction of inducible nitric oxide synthase [98]. In another study, saline irrigation with xylitol was applied by adding $4 \mathrm{~g}$ of pharmaceutical-grade xylitol and $2 \mathrm{mg}$ of sodium to $240 \mathrm{~mL}$ of distilled water [99]. Despite the relatively low concentration of xylitol, this study also showed better symptomatic questionnaire results in the group in which xylitol irrigation was applied. In particular, better results have been observed in patients with allergies. However, there was no difference in the Lund-Kennedy score of the radiologic results between the two groups. Based on the xylitol irrigation studies reported so far, the GDG had several discussions on the policy level that should be recommended. Despite the relatively large number of controlled trials, the usage differed between each study, and an insufficient analysis of the results could be performed due to these differences. Still, considering the complications of general nasal irrigation and the stability of xylitol, the benefits were deemed to outweigh any harm. Finally, the policy level was set to an "option." We analyzed three RCTs related to honey. Two studies were conducted with saline irrigation and manuka honey, while the other used thyme honey [100-102]. Usually, honey is named after the predominant nectar source(s) visited by the bees. The studies were analyzed for recurrent CRS and the postoperative period. There were no significant differences in the symptomatic questionnaire scores, endoscopic findings, and radiologic findings between the group that received saline irrigation with honey and the group that received saline irrigation only in all studies. In addition, there was no difference in the frequency and type of complications between the two groups. No specific complications were found in the group that received saline irrigation with honey, other than the general saline irrigation complications. However, the GDG recommended against this therapy due to potential allergies to honey and the high cost of honey. In addition, there were four Italian studies on nasal irrigation using thermal water (hot spring water) [103-106]. In general, these showed promising results in terms of symptom improvement and endoscopic findings, but there was a lack of consistency in the use and results. Furthermore, we judged that the generalizability was insufficient because the studies were only conducted in one country. Two RCTs used antiseptic fluid for nasal irrigation $[107,108]$. In one of these, 43 patients with CRS who used "low concentration hypochlorous acid" demonstrated better SNOT-20 results [107]. Two nasal irrigation studies used dexpanthenol, which is primarily used in ointments for moisturizing and promoting wound healing. These studies showed that there was an increase in mucociliary clearance. However, there were no significant differences between the groups in which dexpanthenol was and was not applied $[109,110]$. There was one nasal irrigation study that used xyloglucan with mucin-like properties as a natural polysaccharide. Compared with saline spray, the group in which xyloglucan spray was applied showed better symptom improvement [111]. Lastly, one nasal irrigation study used baby shampoo, a surfactant. The groups that did and did not use baby shampoo both showed good results, with no significant difference [112]. However, the group that used the baby shampoo presented more complications and lower tolerability.

Statement 8. Irrigation fluid preparation: clinicians should recommend an appropriate irrigation fluid preparation method for patients with CRS or those who have undergone ESS. For irrigation fluid, bottled or distilled water should preferably be used. If tap water is used, boil it for at least 5 minutes and cool before use or expose it to ultraviolet (UV) light for at least 45 seconds. Recommendation based on a case-control study of lab research and a preponderance of benefits over harm.

\section{Action statement profile: 8}

- Quality improvement opportunity: To prevent retrograde infection or postoperative infection by ensuring that the irrigation fluid is appropriately prepared.

- Level of confidence in evidence: Medium.

- Aggregate evidence quality: Grade C, based on observational and case-control studies.

- Benefits: Appropriate preparation prevents unnecessary retrograde infection or postoperative infection.

- Risk, harm, and cost: None.

- Benefit-harm assessment: Preponderance of benefits over harm.

- Value judgments: None.

- Intentional vagueness: None.

- Role of patient preferences: None.

- Exclusions: None.

- Policy level: Recommendation. 
- Differences of opinion: None.

\section{Supporting text}

The purpose of this statement is to prevent retrograde infection and postoperative infection through the device or fluid used by promoting the proper management of irrigation devices and preparation of irrigation fluid. Nasal irrigation is an essential treatment for CRS and post-ESS wound management. Studies on the characteristics and fluid additives of various irrigation fluids are being conducted. This guideline also presents a "recommended" policy level through an analysis of these studies. Clinical trials of contaminated or non-well-managed devices or fluids cannot be conducted because it is unethical to conduct studies with poorly sterilized or contaminated devices or fluids. Therefore, the GDG determined the recommendation grade through the results of reliable laboratory and observational clinical studies. Moreover, we considered the clinical importance, potential harm to patients, and convenience of application. It is essential to prepare the irrigation fluid correctly. Usually, irrigation device manufacturers or clinicians recommend using sterile bottled water or distilled water [113]. However, a study showed that $48 \%$ of patients used tap water directly without boiling it, and it has been reported that $27 \%$ of patients did not disinfect the bottle used [114]. Tap water containing Naegleria fowleri caused amebic meningoencephalitis through the olfactory nerve during nasal irrigation, resulting in the death of a patient in the US [115]. Even in sterilized fluid, infectious pathogens can grow again within a short period; therefore, refrigeration is required [116]. In addition, fluid contamination can occur in isotonic and hypotonic fluids. Therefore, it is recommended to boil the fluid for at least 5 minutes and cool it down or expose it to UV light for at least 45 seconds [117].

Statement 9. Equipment: clinicians should recommend nasal irrigation performed by high-volume with low- or high-pressure delivery rather than low-volume with low- or high-pressure delivery in patients with CRS. Recommendation based on RCTs, observational studies, and a preponderance of benefits over harm.

\section{Action statement profile: 9}

- Quality improvement opportunity: To promote the efficacy of nasal irrigation in patients with CRS.

- Level of confidence in evidence: Medium.

- Aggregate evidence quality: Grade B, based on RCTs and observational studies.

- Benefits: High-volume delivery is more effective than low-volume delivery at penetrating the paranasal sinuses, which may be important for mechanical cleaning/lavage and potential drug delivery.
- Risk, harm, and cost: High-volume nasal irrigation can cause patient discomfort, eustachian tube dysfunction, or potential mucosal trauma to the nose, resulting in nose bleeds.

- Benefit-harm assessment: Preponderance of benefits over harm.

- Value judgments: None.

- Intentional vagueness: There have been several well-designed studies, including RCTs. Therefore, the GDG decided to set the policy level as a "recommendation."

- Role of patient preferences: Some patients may decline nasal irrigation with a high volume and instead want to perform nasal irrigation with a low volume.

- Exclusions: Patients who have an intolerance to high-volume irrigation should continue with low-volume nasal saline irrigation.

- Policy level: Recommendation.

- Differences of opinion: None.

\section{Supporting text}

Various studies have reported that different types of equipment provide different volumes and pressures of nasal saline delivery, which may impact irrigation penetration into the paranasal sinuses [118-125]. Generally, the delivery technique of nasal irrigation can be categorized based on the volume and pressure of delivery into four groups [124]. Pressure is defined as low-pressure when devices simply use gravity, whereas it is defined as high-pressure when equipment is powered or manually squeezed to generate a pressurized stream $[124,125]$. The volume is categorized as high-volume when the total volume of the irrigation solution is greater than $200 \mathrm{~mL}$ [124].

- Low-volume and low-pressure devices include nasal drops and sprays.

- Low-volume and high-pressure devices include pressurized spray and nasal irrigation using syringes.

- High-volume and low-pressure devices include nasal irrigation using pots and nebulizers.

- High-volume and high-pressure devices include nasal irrigation using squeeze bottles, bulb syringes, and powered irrigation devices.

High-volume nasal irrigation can occasionally be associated with a higher incidence of nasal discomfort, burning, epistaxis, and eustachian tube dysfunction than low-volume nasal irrigation $[125,126]$. Low-volume nasal irrigation using nasal drops and sprays can fail to reliably reach the entire paranasal sinuses and has a somewhat limited distribution to the middle meatus and sphenoid sinus area $[46,127]$. In addition, a nebulizer with a large particle size may improve distribution to the inferior and middle turbinates. However, there is no clear superiority of nebulization over other low-volume devices, such as drops or sprays [124]. 
Statement 10. Disinfection: clinicians should recommend the following techniques for appropriate irrigation equipment care to patients with CRS or those who have undergone ESS. Irrigation equipment (according to the equipment material and manufacturer's recommendations, if possible) should be boiled (for more than 2 minutes) or microwaved for 1 minute and 30 seconds regularly before and after use. Recommendation based on a case-control study of lab research and a preponderance of benefits over harm.

\section{Action statement profile: 10}

- Quality improvement opportunity: To prevent retrograde infection or postoperative infection through the device used by disinfecting the irrigation device.

- Level of confidence in evidence: Medium.

- Aggregate evidence quality: Grade C, based on observational and case-control studies.

- Benefits: Prevent unnecessary retrograde infection or postoperative infection.

- Risk, harm, and cost: None.

- Benefit-harm assessment: Preponderance of benefits over harm.

- Value judgments: None.

- Intentional vagueness: The cited studies used various devices with various purposes. Considering the various manufacturers, shapes, and materials of the irrigation devices, it is thought that the appropriate disinfection method will differ from device to device.

- Role of patient preferences: None.

- Exclusions: None.

- Policy level: Recommendation.

- Differences of opinion: None.

\section{Supporting text}

Irrigation devices are fluid-specific [107] and are usually made up of a bulb syringe, pot-shaped bottle, and squeezable irrigation device. Various devices have been developed, from simple bulb syringes to devices with one-way valves to prevent contamination and ensure ease of use $[128,129]$. However, one study showed that contamination was observed after 1 week of use regardless of the bottle design [130]. Even in a one-way valve device, which helps prevent the inflow of external contaminated material, contamination was observed 1 week after use, and it was reported that part of the valve harbored bacteria [128]. Various irrigation devices have been developed that aim to prevent contamination and be more convenient to use. However, none of these devices seem to be significantly better for preventing contamination. The most common bacteria found in contaminated bottles have been reported to be Pseudomonas aeruginosa and Staphylococcus aureus [131-134]. Even if bot- tles were disinfected following the manufacturers' recommended cleaning method, they were contaminated again after 1 week. However, there have been no cases of contaminated bottles causing postoperative infections [132]. The disinfection effect was high after the bottles were boiled for more than 2 minutes or microwaved for more than 1 minute and 30 seconds; the longer the bottle was microwaved or boiled, the higher the sterilization effect. However, the irrigation bottle became deformed [135-138]. Despite these findings, a study that compared alcohol immersion and microwave disinfection for catheters reported cases of recontamination even after microwave disinfection; hence, care should be taken [139]. Therefore, clinicians should recommend that bottles be sterilized in a microwave for at least 1 minute and 30 seconds before and after use.

Statement 11. Posture: clinicians may recommend the head down-and-forward position as being better for high-volume nasal irrigation, whereas the nose-to-ceiling position is more effective at delivering low-volume nasal irrigation. Option based on observational studies and a preponderance of benefits over harm.

\section{Action statement profile: 11}

- Quality improvement opportunity: To promote the efficacy of nasal irrigation in patients with CRS.

- Level of confidence in evidence: Medium.

- Aggregate evidence quality: Grade C, based on observational studies.

- Benefits: Improved penetration of nasal irrigation into the sinuses, which may be important for mechanical cleaning/lavage and potential drug delivery.

- Risk, harm, and cost: None.

- Benefit-harm assessment: Preponderance of benefits over harm.

- Value judgments: None.

- Intentional vagueness: There have been several well-designed studies. however, only a small number could be found, and none were randomly designed. Despite this, the GDG thought that the benefits outweighed any harm. Therefore, the policy level was set to an "option."

- Role of patient preferences: Some patients may not wish to perform specific head positions unfamiliar to them.

- Exclusions: None.

- Policy level: Option.

- Differences of opinion: None.

\section{Supporting text}

Several studies have attempted to investigate the advantages of various head positions, including head upright, head down-andforward, nose-to-ceiling, and lateral head low (Fig. 2) [124,125, 


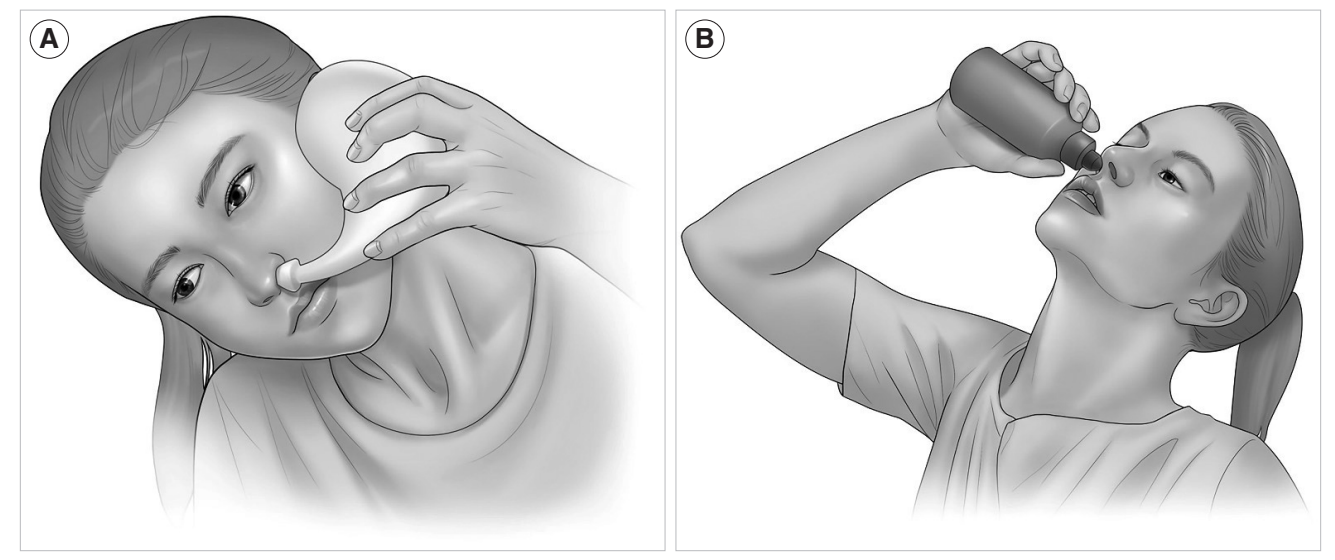

Fig. 2. Posture for nasal irrigation. Two head positions: (A) head down-and-forward position and (B) nose-to-ceiling position.

140-143]. Overall, the nose-to-ceiling position showed a greater distribution of nasal irrigation delivered by low-volume techniques such as drops or sprays compared with other head positions. However, high-volume nasal irrigation techniques using pots and squeeze bottles showed a more effective distribution in the head down-and-forward position. A recent computational fluid dynamics model using cadavers showed that the nose-toceiling position was superior to the head down-and-forward position in delivering high-volume saline irrigation to the sphenoid sinuses [144]. This finding means that the head position is less critical when using high-volume delivery; however, the head position is more important when using low-volume delivery because it leads to less effective penetration of paranasal sinuses.

\section{RESEARCH NEEDS}

Although many clinical trials have been published on nasal irrigation, the evidence level of each trial is often not high. It is not easy to consistently interpret the study results because the types and contents of the solutions and additives used vary between the trials. For this reason, there is a conflict between published clinical guidelines for nasal irrigation and the results of metaanalyses. Moreover, the additional agents varied widely between guidelines depending on the treatment conditions and culture in the country where it was published. For example, for saline tonicity, the 2020 EPOS guideline recommends nasal irrigation using isotonic saline or Ringer's lactate solution [7]. However, a systematic review and meta-analysis published in 2020 reported that some studies showed that hypertonic saline was more effective in improving symptoms [58]. Moreover, manuka honey, baby shampoo, and Dead Sea salt were included in several studies. However, these substances are not widely used domestically in Korea. In addition, many clinicians recommend mixing steroids, antibiotics, antibiotic ointments, and sodium hyaluronate with irrigation solutions. However, these do not fall under the drug approval indication. Therefore, these agents are likely to be used as off-label indications.

Furthermore, many patients ask their doctor how many times a day they should irrigate their nasal cavities and what amount they should use. However, no studies have yet provided accurate answers to these questions. Accordingly, the GDG makes the following suggestions. (1) It is necessary to establish an appropriate standard through standardized research or the consensus of experts. (2) It is necessary to standardize the dosage and administration of steroids such as budesonide and antibiotics such as mupirocin mixed with washing solution, and pharmacokinetic studies should be conducted on their use for nasal washing. (3) Research on nasal washing using thermal water, Dead Sea salt, Ems mineral salts, and honey, which are difficult to standardize in terms of ingredients, should be avoided. A standard composition is required before drugs are applied in clinical practice.

\section{DISCLAIMER}

The GDG, supported by the KORL-HNS, did not attempt to provide guidance on all aspects of nasal irrigation. Instead, we have attempted to help care providers by providing evidencebased information on areas that may be particularly confusing when prescribing and explaining nasal irrigation to patients. However, as medical knowledge and technology are continually evolving and expanding, this guideline may be revised and new sections added in the future. Clinicians can also apply their own techniques based on their clinical judgment and evidence that may not be included in this guideline. Such methods may be included in future guidelines if they are scientifically verified. The GDG emphasizes that this practice guideline does not contain information on all methods of care and treatment decisions. Thus, there may be efficacious treatment methods that are not included in this practice guideline. 


\section{CONFLICT OF INTEREST}

No potential conflict of interest relevant to this article was reported.

\section{ACKNOWLEDGMENTS}

The authors express their deep gratitude to Prof. Yang-Sun Cho, the Chairman of the Korean Society of OtorhinolaryngologyHead and Neck surgery, and Prof. Sung Wan Kim, the President of the Korean Rhinologic Society, for their full support in the writing of this clinical practice guideline.

\section{ORCID}

$\begin{array}{ll}\text { Do-Yang Park } & \text { http://orcid.org/0000-0001-9969-3051 } \\ \text { Ji Ho Choi } & \text { http://orcid.org/0000-0002-5194-930X } \\ \text { Dong-Kyu Kim } & \text { http://orcid.org/0000-0003-4917-0177 } \\ \text { Yong Gi Jung } & \text { http://orcid.org/0000-0001-7456-849X } \\ \text { Sue Jean Mun } & \text { http://orcid.org/0000-0003-4486-7178 } \\ \text { Hyun Jin Min } & \text { http://orcid.org/0000-0003-3075-1350 } \\ \text { Soo Kyoung Park } & \text { http://orcid.org/0000-0002-5163-536X } \\ \text { Jae-Min Shin } & \text { http://orcid.org/0000-0002-2090-9612 } \\ \text { Hyung Chae Yang } & \text { http://orcid.org/0000-0002-9187-1367 } \\ \text { Seung-No Hong } & \text { http://orcid.org/0000-0002-5759-9929 } \\ \text { Ji-Hun Mo } & \text { http://orcid.org/0000-0003-1331-364X }\end{array}$

\section{AUTHOR CONTRIBUTIONS}

Conceptualization: DYP, JHC, DKK, YGJ. Methodology: DYP, JHC, DKK, YGJ. Project administration: JYG. Visualization: DYP. Writing-original draft: DYP, JHC, DKK, YGJ. Writing-review \& editing: all authors.

\section{REFERENCES}

1. Kim do H, Han K, Kim SW. Effect of chronic rhinosinusitis with or without nasal polyp on quality of life in South Korea: 5th Korea National Health and Nutrition Examination Survey Korean. Clin Exp Otorhinolaryngol. 2016 Jun;9(2):150-6.

2. Venkatraman G, Likosky DS, ZhouW, Finlayson SR, Goodman DC. Trends in endoscopic sinus surgery rates in the Medicare population. Arch Otolaryngol Head Neck Surg. 2010 May;136(5):426-30.

3. Ference EH, Suh JD, Tan BK, Smith SS. How often is sinus surgery performed for chronic rhinosinusitis with versus without nasal polyps? Am J Rhinol Allergy. 2018 Jan;32(1):34-9.

4. Chapurin N, Pynnonen MA, Roberts R, Schulz K, Shin JJ, Witsell $\mathrm{DL}$, et al. CHEER national study of chronic rhinosinusitis practice patterns: disease comorbidities and factors associated with surgery. Otolaryngol Head Neck Surg. 2017 Apr;156(4):751-6.

5. Mahboubi H, Bhandarkar ND. Trends of ambulatory sinus surgery for chronic rhinosinusitis. Int Forum Allergy Rhinol. 2015 Apr;5(4): 318-25.

6. Rosenfeld RM, Piccirillo JF, Chandrasekhar SS, Brook I, Ashok Kumar K, Kramper M, et al. Clinical practice guideline (update): adult sinusitis. Otolaryngol Head Neck Surg. 2015 Apr;152(2 Suppl):S1S39.

7. Fokkens WJ, Lund VJ, Hopkins C, Hellings PW, Kern R, Reitsma S, et al. European Position Paper on Rhinosinusitis and Nasal Polyps 2020. Rhinology. 2020 Feb;58(Suppl S29):1-464.

8. Craig JR, Zhao K, Doan N, Khalili S, Lee JY,Adappa ND, et al. Cadaveric validation study of computational fluid dynamics model of sinus irrigations before and after sinus surgery. Int Forum Allergy Rhinol. 2016 Apr;6(4):423-8.

9. Govindaraju R, Cherian L, Macias-Valle L, Murphy J, Gouzos M, Vreugde S, et al. Extent of maxillary sinus surgery and its effect on instrument access, irrigation penetration, and disease clearance. Int Forum Allergy Rhinol. 2019 Oct;9(10):1097-104.

10. Grayson JW, Cavada M, Wong E, Lien B, Duvnjak M, Campbell R, et al. Effects of sphenoid surgery on nasal irrigation delivery. Int Forum Allergy Rhinol. 2019 Sep;9(9):971-6.

11. Inthavong K, Shang Y, Wong E, Singh N. Characterization of nasal irrigation flow from a squeeze bottle using computational fluid dynamics. Int Forum Allergy Rhinol. 2020 Jan;10(1):29-40.

12. Zhao K, Craig JR, Cohen NA, Adappa ND, Khalili S, Palmer JN. Sinus irrigations before and after surgery: visualization through computational fluid dynamics simulations. Laryngoscope. 2016 Mar;126(3):E90-6.

13. Principi N, Esposito S. Nasal irrigation: an imprecisely defined medical procedure. Int J Environ Res Public Health. 2017 May;14(5): 516.

14. Sanan A, Rabinowitz M, Rosen M, Nyquist G. Topical therapies for refractory chronic rhinosinusitis. Otolaryngol Clin North Am. 2017 Feb;50(1):129-41.

15. Patel ZM, Thamboo A, Rudmik L, Nayak JV, Smith TL, Hwang PH. Surgical therapy vs continued medical therapy for medically refractory chronic rhinosinusitis: a systematic review and meta-analysis. Int Forum Allergy Rhinol. 2017 Feb;7(2):119-27.

16. Adappa ND, Wei CC, Palmer JN. Nasal irrigation with or without drugs: the evidence. Curr Opin Otolaryngol Head Neck Surg. 2012 Feb;20(1):53-7.

17. Shi JB, Fu QL, Zhang H, Cheng L, Wang YJ, Zhu DD, et al. Epidemiology of chronic rhinosinusitis: results from a cross-sectional survey in seven Chinese cities. Allergy. 2015 May;70(5):533-9.

18. Hirsch AG, StewartWF, Sundaresan AS, Young AJ, KennedyTL, Scott Greene J, et al. Nasal and sinus symptoms and chronic rhinosinusitis in a population-based sample. Allergy. $2017 \mathrm{Feb}$;2(2):274-81.

19. Blackwell DL, Lucas JW, Clarke TC. Summary health statistics for U.S. adults: national health interview survey, 2012. Vital Health Stat 10. 2014 Feb;(260):1-161.

20. Ahn JC, Kim JW, Lee CH, Rhee CS. Prevalence and risk factors of chronic rhinosinusitus, allergic rhinitis, and nasal septal deviation: results of the Korean National Health and Nutrition Survey 20082012. JAMA Otolaryngol Head Neck Surg. 2016 Feb;142(2):162-7.

21. Hirsch AG, Nordberg C, Bandeen-Roche K, Tan BK, Schleimer RP, Kern RC, et al. Radiologic sinus inflammation and symptoms of chronic rhinosinusitis in a population-based sample. Allergy. 2020 Apr;75(4):911-20.

22. Tomassen P, Newson RB, Hoffmans R, Lotvall J, Cardell LO, Gunnbjornsdottir M, et al. Reliability of EP3OS symptom criteria and nasal endoscopy in the assessment of chronic rhinosinusitis: a GA ${ }^{2}$ LEN study. Allergy. 2011 Apr;66(4):556-61.

23. Dietz de Loos D, Lourijsen ES, Wildeman MA, Freling NJ, Wolvers $\mathrm{MD}$, Reitsma S, et al. Prevalence of chronic rhinosinusitis in the general population based on sinus radiology and symptomatology. 
J Allergy Clin Immunol. 2019 Mar;143(3):1207-14.

24. Anand VK. Epidemiology and economic impact of rhinosinusitis. Ann Otol Rhinol Laryngol Suppl. 2004 May;193:3-5.

25. Ray NF, Baraniuk JN, Thamer M, Rinehart CS, Gergen PJ, Kaliner M, et al. Healthcare expenditures for sinusitis in 1996: contributions of asthma, rhinitis, and other airway disorders. J Allergy Clin Immunol. 1999 Mar;103(3 Pt 1):408-14.

26. Wahid NW, Smith R, Clark A, Salam M, Philpott CM. The socioeconomic cost of chronic rhinosinusitis study. Rhinology. 2020 Apr; 58(2):112-25.

27. Lourijsen ES, Fokkens WJ, Reitsma S. Direct and indirect costs of adult patients with chronic rhinosinusitis with nasal polyps. Rhinology. 2020 Jun;58(3):213-7.

28. Bhattacharyya N.Assessing the additional disease burden of polyps in chronic rhinosinusitis. Ann Otol Rhinol Laryngol. 2009 Mar; 118(3):185-9.

29. Blackwell DL, Collins JG, Coles R. Summary health statistics for U.S. adults: National Health Interview Survey, 1997. Vital Health Stat 10. 2002 May;(205):1-109.

30. Goetzel RZ, Hawkins K, Ozminkowski RJ, Wang S. The health and productivity cost burden of the "top 10 " physical and mental health conditions affecting six large U.S. employers in 1999. J Occup Environ Med. 2003 Jan;45(1):5-14.

31. Rudmik L. Economics of chronic rhinosinusitis. Curr Allergy Asthma Rep. 2017 Apr;17(4):20.

32. Rudmik L, SmithTL, Schlosser RJ, Hwang PH, Mace JC, Soler ZM. Productivity costs in patients with refractory chronic rhinosinusitis. Laryngoscope. 2014 Sep;124(9):2007-12.

33. Remenschneider AK, Scangas G, Meier JC, Gray ST, Holbrook EH, Gliklich RE, et al. EQ-5D-derived health utility values in patients undergoing surgery for chronic rhinosinusitis. Laryngoscope. 2015 May;125(5):1056-61.

34. Stjarne P, Odeback P, Stallberg B, Lundberg J, Olsson P. High costs and burden of illness in acute rhinosinusitis: real-life treatment patterns and outcomes in Swedish primary care. Prim Care Respir J. 2012 Jun;21(2):174-9.

35. Teul I, Zbislawski W, Baran S, Czerwinski F, Lorkowski J. Quality of life of patients with diseases of sinuses. J Physiol Pharmacol. 2007 Nov;58 Suppl 5(Pt 2):691-7.

36. Gliklich RE, Metson R. The health impact of chronic sinusitis in patients seeking otolaryngologic care. Otolaryngol Head Neck Surg. 1995 Jul;113(1):104-9.

37. Garbutt J, Spitznagel E, Piccirillo J. Use of the modified SNOT-16 in primary care patients with clinically diagnosed acute rhinosinusitis. Arch Otolaryngol Head Neck Surg. 2011 Aug;137(8):792-7.

38. Hopkins C, Browne JP, Slack R, Lund V,Topham J, Reeves B, et al. The national comparative audit of surgery for nasal polyposis and chronic rhinosinusitis. Clin Otolaryngol. 2006 Oct;31(5):390-8.

39. Rudmik L, Mace J, Soler ZM, SmithTL. Long-term utility outcomes in patients undergoing endoscopic sinus surgery. Laryngoscope. 2014 Jan;124(1):19-23.

40. Chester AC, Sindwani R, Smith TL, Bhattacharyya N. Fatigue improvement following endoscopic sinus surgery: a systematic review and meta-analysis. Laryngoscope. 2008 Apr;118(4):730-9.

41. Chester AC, Sindwani R, Smith TL, Bhattacharyya N. Systematic review of change in bodily pain after sinus surgery. Otolaryngol Head Neck Surg. 2008 Dec;139(6):759-65.

42. Soler ZM, Wittenberg E, Schlosser RJ, Mace JC, Smith TL. Health state utility values in patients undergoing endoscopic sinus surgery. Laryngoscope. 2011 Dec;121(12):2672-8.

43. Rosenfeld RM, Shiffman RN, Robertson P; Department of Otolaryngology State University of New York Downstate. Clinical Practice Guideline Development Manual, Third Edition: a quality-driven approach for translating evidence into action. Otolaryngol Head
Neck Surg. 2013 Jan;148(1 Suppl):S1-55.

44. American Academy of Pediatrics Steering Committee on Quality Improvement and Management. Classifying recommendations for clinical practice guidelines. Pediatrics. 2004 Sep;114(3):874-7.

45. Chong LY, Head K, Hopkins C, Philpott C, Glew S, Scadding G, et al. Saline irrigation for chronic rhinosinusitis. Cochrane Database Syst Rev. 2016 Apr;4(4):CD011995.

46. Orlandi RR, Kingdom TT, Smith TL, Bleier B, DeConde A, Luong $\mathrm{AU}$, et al. International consensus statement on allergy and rhinology: rhinosinusitis 2021. Int Forum Allergy Rhinol. 2021 Mar;11(3): 213-739.

47. Orlandi RR, KingdomTT, Hwang PH. International Consensus Statement on Allergy and Rhinology: rhinosinusitis executive summary. Int Forum Allergy Rhinol. 2016 Feb;6 Suppl 1:S3-21.

48. Baraniuk JN, Ali M, Yuta A, Fang SY, Naranch K. Hypertonic saline nasal provocation stimulates nociceptive nerves, substance $P$ release, and glandular mucous exocytosis in normal humans. Am J Respir Crit Care Med. 1999 Aug;160(2):655-62.

49. Giotakis AI, Karow EM, Scheithauer MO, Weber R, Riechelmann H. Saline irrigations following sinus surgery: a controlled, single blinded, randomized trial. Rhinology. 2016 Dec;54(4):302-10.

50. Freeman SR, Sivayoham ES, Jepson K, de Carpentier J. A preliminary randomised controlled trial evaluating the efficacy of saline douching following endoscopic sinus surgery. Clin Otolaryngol. 2008 Oct;33(5):462-5.

51. Wang J, Shen L, Huang ZQ, Luo Q, Li MY,Tu JH, et al. Efficacy of buffered hypertonic seawater in different phenotypes of chronic rhinosinusitis with nasal polyps after endoscopic sinus surgery: a randomized double-blind study. Am J Otolaryngol. 2020;41(5): 102554.

52. Pinto JM, Elwany S, Baroody FM, Naclerio RM. Effects of saline sprays on symptoms after endoscopic sinus surgery. Am J Rhinol. 2006 Mar-Apr;20(2):191-6.

53. Hauptman G, Ryan MW. The effect of saline solutions on nasal patency and mucociliary clearance in rhinosinusitis patients. Otolaryngol Head Neck Surg. 2007 Nov;137(5):815-21.

54. Nikakhlagh S, Abshirini H, Lotfi M, Mohammad S, Mohammadi NS. A comparison between the effects of nasal lavage with hypertonic, isotonic and hypotonic saline solutions for the treatment of chronic sinusitis. J Glob Pharma Technol. 2016 Jan;8(12):68-73.

55. Ural A, Oktemer TK, Kizil Y, Ileri F, Uslu S. Impact of isotonic and hypertonic saline solutions on mucociliary activity in various nasal pathologies: clinical study. J Laryngol Otol. 2009 May;123(5):51721.

56. Berjis N, Sonbolastan SM, Okhovat SH, Narimani AA, Razmjui J. Normal saline versus hypertonic 3\% saline: it's efficacy in nonacute rhinosinusitis. Iran J Otorhinolaryngol. 2011 Winter;23(1): 23-8.

57. Culig J, Leppee M,Vceva A, Djanic D. Efficiency of hypertonic and isotonic seawater solutions in chronic rhinosinusitis. Med Glas (Zenica). 2010 Aug;7(2):116-23.

58. Liu L, Pan M, Li Y, Tan G, Yang Y. Efficacy of nasal irrigation with hypertonic saline on chronic rhinosinusitis: systematic review and meta-analysis. Braz J Otorhinolaryngol. 2020 Sep-Oct;86(5):639-46.

59. Kanjanawasee D, Seresirikachorn K, Chitsuthipakorn W, Snidvongs $\mathrm{K}$. Hypertonic saline versus isotonic saline nasal irrigation: systematic review and meta-analysis. Am J Rhinol Allergy. 2018 Jul;32(4): 269-79.

60. Low TH, Woods CM, Ullah S, Carney AS. A double-blind randomized controlled trial of normal saline, lactated Ringer's, and hypertonic saline nasal irrigation solution after endoscopic sinus surgery. Am J Rhinol Allergy. 2014 May-Jun;28(3):225-31.

61. Green A, Smallman LA, Logan AC, Drake-Lee AB. The effect of temperature on nasal ciliary beat frequency. Clin Otolaryngol Al- 
lied Sci. 1995 Apr;20(2):178-80.

62. Mwimbi XK, Muimo R, Green MW, MehtaA. Making human nasal cilia beat in the cold: a real time assay for cell signalling. Cell Signal. 2003 Apr;15(4):395-402.

63. Nimsakul S, Ruxrungtham S, Chusakul S, Kanjanaumporn J,Aeumjaturapat S, Snidvongs K. Does heating up saline for nasal irrigation improve mucociliary function in chronic rhinosinusitis? Am J Rhinol Allergy. 2018 Mar;32(2):106-11.

64. Sauvalle M, Alvo A. Effect of the temperature of nasal lavages on mucociliary clearance: a randomised controlled trial. Eur Arch Otorhinolaryngol. 2018 Sep;275(9):2403-6.

65. Adelson RT, Kennedy DW. Paranasal sinus exostoses: possible correlation with cold temperature nasal irrigation after endoscopic sinus surgery. Laryngoscope. 2013 Jan;123(1):24-7.

66. Yoon HY, Lee HS, Kim IH, Hwang SH. Post-operative corticosteroid irrigation for chronic rhinosinusitis after endoscopic sinus surgery: a meta-analysis. Clin Otolaryngol. 2018 Apr;43(2):525-32.

67. Harvey RJ, Snidvongs K, Kalish LH, Oakley GM, Sacks R. Corticosteroid nasal irrigations are more effective than simple sprays in a randomized double-blinded placebo-controlled trial for chronic rhinosinusitis after sinus surgery. Int Forum Allergy Rhinol. 2018 Apr; 8(4):461-70.

68. Jang DW, Lachanas VA, Segel J, Kountakis SE. Budesonide nasal irrigations in the postoperative management of chronic rhinosinusitis. Int Forum Allergy Rhinol. 2013 Sep;3(9):708-11.

69. Kosugi EM, Moussalem GF, Simoes JC, Souza Rde P, Chen VG, Saraceni Neto P, et al.Topical therapy with high-volume budesonide nasal irrigations in difficult-to-treat chronic rhinosinusitis. Braz J Otorhinolaryngol. 2016 Mar-Apr;82(2):191-7.

70. Kang TW, Chung JH, Cho SH, Lee SH, Kim KR, Jeong JH. The effectiveness of budesonide nasal irrigation after endoscopic sinus surgery in chronic rhinosinusitis with asthma. Clin Exp Otorhinolaryngol. 2017 Mar;10(1):91-6.

71. Tait S, Kallogjeri D, Suko J, Kukuljan S, Schneider J, Piccirillo JF. Effect of budesonide added to large-volume, low-pressure saline sinus irrigation for chronic rhinosinusitis: a randomized clinical trial. JAMA Otolaryngol Head Neck Surg. 2018 Jul;144(7):605-12.

72. Rawal RB, Deal AM, Ebert CS Jr, Dhandha VH, Mitchell CA, Hang $\mathrm{AX}$, et al. Post-operative budesonide irrigations for patients with polyposis: a blinded, randomized controlled trial. Rhinology. 2015 Sep;53(3):227-34.

73. Seiberling KA, Chang DF, Nyirady J, Park F, Church CA. Effect of intranasal budesonide irrigations on intraocular pressure. Int Forum Allergy Rhinol. 2013 Sep;3(9):704-7.

74. Man LX, Farhood Z, Luong A, Fakhri S, Feldman RM, Orlander PR, et al. The effect of intranasal fluticasone propionate irrigations on salivary cortisol, intraocular pressure, and posterior subcapsular cataracts in postsurgical chronic rhinosinusitis patients. Int Forum Allergy Rhinol. 2013 Dec;3(12):953-7.

75. Smith KA, French G, Mechor B, Rudmik L. Safety of long-term high-volume sinonasal budesonide irrigations for chronic rhinosinusitis. Int Forum Allergy Rhinol. 2016 Mar;6(3):228-32.

76. Soudry E, Wang J, Vaezeafshar R, Katznelson L, Hwang PH. Safety analysis of long-term budesonide nasal irrigations in patients with chronic rhinosinusitis post endoscopic sinus surgery. Int Forum Allergy Rhinol. 2016 Jun;6(6):568-72.

77. Dawson B, Gutteridge I, Cervin A, Robinson D. The effects of nasal lavage with betamethasone cream post-endoscopic sinus surgery: clinical trial. J Laryngol Otol. 2018 Feb;132(2):143-9.

78. Tan NC, Psaltis AJ. Latest developments on topical therapies in chronic rhinosinusitis. Curr Opin Otolaryngol Head Neck Surg. 2020 Feb; 28(1):25-30.

79. Snidvongs K, Thanaviratananich S. Update on intranasal medications in rhinosinusitis. Curr Allergy Asthma Rep. 2017 Jul;17(7):47.
80. Grayson JW, Harvey RJ.Topical corticosteroid irrigations in chronic rhinosinusitis. Int Forum Allergy Rhinol. 2019 May;9(S1):S9-15.

81. Solares CA, Batra PS, Hall GS, Citardi MJ.Treatment of chronic rhinosinusitis exacerbations due to methicillin-resistant Staphylococcus aureus with mupirocin irrigations. Am J Otolaryngol. 2006 MayJun;27(3):161-5.

82. Uren B, Psaltis A, Wormald PJ. Nasal lavage with mupirocin for the treatment of surgically recalcitrant chronic rhinosinusitis. Laryngoscope. 2008 Sep;118(9):1677-80.

83. Jervis-Bardy J, Boase S, Psaltis A, Foreman A, Wormald PJ. A randomized trial of mupirocin sinonasal rinses versus saline in surgically recalcitrant staphylococcal chronic rhinosinusitis. Laryngoscope. 2012 Oct;122(10):2148-53.

84. Ebbens FA, Scadding GK, Badia L, Hellings PW, Jorissen M, Mullol $\mathrm{J}$, et al. Amphotericin B nasal lavages: not a solution for patients with chronic rhinosinusitis. J Allergy Clin Immunol. 2006 Nov;118(5): 1149-56.

85. Liang KL, Su MC, Shiao JY,Tseng HC, Hsin CH, Lin JF, et al. Amphotericin $\mathrm{B}$ irrigation for the treatment of chronic rhinosinusitis without nasal polyps: a randomized, placebo-controlled, doubleblind study. Am J Rhinol. 2008 Jan-Feb;22(1):52-8.

86. Jiang RS, Hsu SH, Liang KL. Amphotericin B nasal irrigation as an adjuvant therapy after functional endoscopic sinus surgery. Am J Rhinol Allergy. 2015 Nov-Dec;29(6):435-40.

87. Jiang RS, Twu CW, Liang KL. Efficacy of nasal irrigation with 200 $\mu \mathrm{g} / \mathrm{mL}$ amphotericin B after functional endoscopic sinus surgery: a randomized, placebo-controlled, double-blind study. Int Forum Allergy Rhinol. 2018 Jan;8(1):41-8.

88. Zia S, Naqvi SU,Ahmed S, Farrukh MS, Sheikh SM. Role of amphotericin B in nasal irrigation for chronic rhinosinusitis with nasal polyps. J Coll Physicians Surg Pak. 2019 Aug;29(8):732-5.

89. Wang T, Su J, Feng Y.The effectiveness topical amphotericin B in the management of chronic rhinosinusitis: a meta-analysis. Eur Arch Otorhinolaryngol. 2015 Aug;272(8):1923-9.

90. Gelardi M, Guglielmi AV, De Candia N, Maffezzoni E, Berardi P, Quaranta N. Effect of sodium hyaluronate on mucociliary clearance after functional endoscopic sinus surgery. Eur Ann Allergy Clin Immunol. 2013 May;45(3):103-8.

91. Macchi A, Terranova P, Digilio E, Castelnuovo P. Hyaluronan plus saline nasal washes in the treatment of rhino-sinusal symptoms in patients undergoing functional endoscopic sinus surgery for rhinosinusal remodeling. Int J Immunopathol Pharmacol. 2013 Jan-Mar; 26(1):137-45.

92. Casale M, Sabatino L, Frari V, Mazzola F, Dell'Aquila R, Baptista P, et al. The potential role of hyaluronan in minimizing symptoms and preventing exacerbations of chronic rhinosinusitis. Am J Rhinol Allergy. 2014 Jul-Aug;28(4):345-8.

93. Cantone E, Castagna G, Sicignano S, Ferranti I, Rega F, Di RubboV, et al. Impact of intranasal sodium hyaluronate on the short-term quality of life of patients undergoing functional endoscopic sinus surgery for chronic rhinosinusitis. Int Forum Allergy Rhinol. 2014 Jun;4(6):484-7.

94. Mozzanica F, Preti A, Gera R, Bulgheroni C, Cardella A, Albera A, et al. Double-blind, randomised controlled trial on the efficacy of saline nasal irrigation with sodium hyaluronate after endoscopic sinus surgery. J Laryngol Otol. 2019 Apr;133(4):300-8.

95. Cantone E, Iengo M. Effect of sodium hyaluronate added to topical corticosteroids in chronic rhinosinusitis with nasal polyposis. Am J Rhinol Allergy. 2016 Sep;30(5):340-3.

96. Savietto E, Marioni G, Maculan P, Pettorelli A, Scarpa B, Simoni E, et al. Effectiveness of micronized nasal irrigations with hyaluronic acid/isotonic saline solution in non-polipoid chronic rhinosinusitis: a prospective, randomized, double-blind, controlled study. Am J Otolaryngol. 2020 Jul-Aug;41(4):102502. 
97. Weissman JD, Fernandez F, Hwang PH. Xylitol nasal irrigation in the management of chronic rhinosinusitis: a pilot study. Laryngoscope. 2011 Nov;121(11):2468-72.

98. Lin L, Tang X, Wei J, Dai F, Sun G. Xylitol nasal irrigation in the treatment of chronic rhinosinusitis. Am J Otolaryngol. 2017 Jul-Aug;38(4): 383-9.

99. Kim DH, Kim Y, Lim IG, Cho JH, Park YJ, Kim SW, et al. Effect of postoperative xylitol nasal irrigation on patients with sinonasal diseases. Otolaryngol Head Neck Surg. 2019 Mar;160(3):550-5.

100. Hashemian F, Baghbanian N, Majd Z, Rouini MR, Jahanshahi J, Hashemian F. The effect of thyme honey nasal spray on chronic rhinosinusitis: a double-blind randomized controlled clinical trial. Eur Arch Otorhinolaryngol. 2015 Jun;272(6):1429-35.

101. Lee VS, Humphreys IM, Purcell PL, Davis GE. Manuka honey sinus irrigation for the treatment of chronic rhinosinusitis: a randomized controlled trial. Int Forum Allergy Rhinol. 2017 Apr;7(4): $365-72$.

102. Ooi ML, Jothin A, Bennett C, Ooi EH, Vreugde S, Psaltis AJ, et al. Manuka honey sinus irrigations in recalcitrant chronic rhinosinusitis: phase 1 randomized, single-blinded, placebo-controlled trial. Int Forum Allergy Rhinol. 2019 Dec;9(12):1470-7.

103. Salami A, Dellepiane M, Strinati F, Guastini L, Mora R. Sulphurous thermal water inhalations in the treatment of chronic rhinosinusitis. Rhinology. 2010 Mar;48(1):71-6.

104. Passali FM, Crisanti A, Passali GC, Cianfrone F, Bocchi M, Messineo $\mathrm{G}$, et al. Efficacy of inhalation therapy with water of Salsomaggiore (Italy) in chronic and recurrent nasosinusal inflammation treatment. Clin Ter. 2008 May-Jun;159(3):175-80.

105. Passali D, Lauriello M, Passali GC, Passali FM, Cassano M, Cassano $\mathrm{P}$, et al. Clinical evaluation of the efficacy of Salsomaggiore (Italy) thermal water in the treatment of rhinosinusal pathologies. Clin Ter. 2008 May-Jun;159(3):181-8.

106. Ottaviano G, Marioni G, Staffieri C, Giacomelli L, Marchese-Ragona R, Bertolin A, et al. Effects of sulfurous, salty, bromic, iodic thermal water nasal irrigations in nonallergic chronic rhinosinusitis: a prospective, randomized, double-blind, clinical, and cytological study. Am J Otolaryngol. 2011 May-Jun;32(3):235-9.

107. Yu MS, Kim BH, Kang SH, Lim DJ. Low-concentration hypochlorous acid nasal irrigation for chronic sinonasal symptoms: a prospective randomized placebo-controlled study. Eur Arch Otorhinolaryngol. 2017 Mar;274(3):1527-33.

108. Pigret D, Jankowski R. Management of post-ethmoidectomy crust formation: randomized single-blind clinical trial comparing pressurized seawater versus antiseptic/mucolytic saline. Rhinology. 1996 Mar;34(1):38-40.

109. Fooanant S, Chaiyasate S, Roongrotwattanasiri K. Comparison on the efficacy of dexpanthenol in sea water and saline in postoperative endoscopic sinus surgery. J Med Assoc Thai. 2008 Oct;91(10): 1558-63.

110. Tantilipikorn P, Tunsuriyawong $\mathrm{P}$, Jareoncharsri $\mathrm{P}$, Bedavanija A, Assanasen P, Bunnag C, et al. A randomized, prospective, doubleblind study of the efficacy of dexpanthenol nasal spray on the postoperative treatment of patients with chronic rhinosinusitis after endoscopic sinus surgery. J Med Assoc Thai. 2012 Jan;95(1):58-63.

111. Passali D, Fiorella R, Camaioni A, Villari G, Mora E, Passali GC, et al. Glucan solution nasal spray vs saline in the treatment of chronic rhinosinusitis: a multi-centric double blind randomized clinical trial. Clin Ter. 2007 Mar-Apr;158(2):139-45.

112. Farag AA, Deal AM, McKinney KA, Thorp BD, Senior BA, Ebert CS Jr, et al. Single-blind randomized controlled trial of surfactant vs hypertonic saline irrigation following endoscopic endonasal surgery. Int Forum Allergy Rhinol. 2013 Apr;3(4):276-80.

113. NeilMed Pharmaceuticals Inc. What type of water should I use for my neti pot? [Internet]. Santa Rosa (CA): NeilMed Pharmaceuti- cals Inc; 2021 [cited 2021 Jan 12]. Available from: http://www. neilmed.com/usa/np_water_quality.php\#sthash.YFfdYEeS.dpbs.

114. Sowerby LJ, Wright ED. Tap water or "sterile" water for sinus irrigations: what are our patients using? Int Forum Allergy Rhinol. 2012 Jul-Aug;2(4):300-2.

115. Yoder JS, Straif-Bourgeois S, Roy SL, MooreTA, Visvesvara GS, Ratard RC, et al. Primary amebic meningoencephalitis deaths associated with sinus irrigation using contaminated tap water. Clin Infect Dis. 2012 Nov;55(9):e79-85.

116. Hardy ET, Stringer SP, O'Callaghan R, Arana A, Bierdeman MA, May WL. Strategies for decreasing contamination of homemade nasal saline irrigation solutions. Int Forum Allergy Rhinol. 2016 Feb;6(2):140-2.

117. Ordemann AG, Stanford JK 2nd, Sullivan DC, Reed JM. Can contaminated water be rendered safe for nasal saline irrigations? Laryngoscope. 2017 Jul;127(7):1513-9.

118. van den Berg JW, de Nier LM, Kaper NM, Schilder AG, Venekamp $\mathrm{RP}$, Grolman W, et al. Limited evidence: higher efficacy of nasal saline irrigation over nasal saline spray in chronic rhinosinusitis: an update and reanalysis of the evidence base. Otolaryngol Head Neck Surg. 2014 Jan;150(1):16-21.

119. Pynnonen MA, Mukerji SS, Kim HM,Adams ME,Terrell JE. Nasal saline for chronic sinonasal symptoms: a randomized controlled trial. Arch Otolaryngol Head Neck Surg. 2007 Nov;133(11):111520.

120. Rabago D, Pasic T, Zgierska A, Mundt M, Barrett B, Maberry R. The efficacy of hypertonic saline nasal irrigation for chronic sinonasal symptoms. Otolaryngol Head Neck Surg. 2005 Jul;133(1):3-8.

121. Salib RJ,Talpallikar S, Uppal S, Nair SB. A prospective randomised single-blinded clinical trial comparing the efficacy and tolerability of the nasal douching products Sterimar ${ }^{\mathrm{TM}}$ and Sinus Rinse ${ }^{\mathrm{TM}}$ following functional endoscopic sinus surgery. Clin Otolaryngol. 2013 Aug;38(4):297-305.

122. Taccariello M, Parikh A, Darby Y, Scadding G. Nasal douching as a valuable adjunct in the management of chronic rhinosinusitis. Rhinology. 1999 Mar;37(1):29-32.

123. Heatley DG, McConnell KE, KilleTL, Leverson GE. Nasal irrigation for the alleviation of sinonasal symptoms. Otolaryngol Head Neck Surg. 2001 Jul;125(1):44-8.

124. Thomas WW 3rd, Harvey RJ, Rudmik L, Hwang PH, Schlosser RJ. Distribution of topical agents to the paranasal sinuses: an evidencebased review with recommendations. Int Forum Allergy Rhinol. 2013 Sep;3(9):691-703.

125. Succar EF, Turner JH, Chandra RK. Nasal saline irrigation: a clinical update. Int Forum Allergy Rhinol. 2019 May;9(S1):S4-8.

126. Harvey R, Hannan SA, Badia L, Scadding G. Nasal saline irrigations for the symptoms of chronic rhinosinusitis. Cochrane Database Syst Rev. 2007 Jul;(3):CD006394.

127. MollerW, Schuschnig U, Khadem Saba G, Meyer G, Junge-Hulsing $\mathrm{B}$, Keller M, et al. Pulsating aerosols for drug delivery to the sinuses in healthy volunteers. Otolaryngol Head Neck Surg. 2010 Mar; 142(3):382-8.

128. Foreman A, Wormald PJ. Can bottle design prevent bacterial contamination of nasal irrigation devices? Int Forum Allergy Rhinol. 2011 Jul-Aug;1(4):303-7.

129. Kofonow JM, Bhuskute A, Doghramji L, Palmer JN, Cohen NA, Chiu AG. One-way valve bottle contamination rates in the immediate post-functional endoscopic sinus surgery period. Am J Rhinol Allergy. 2011 Nov-Dec;25(6):393-6.

130. Psaltis AJ, Foreman A, Wormald PJ, Schlosser RJ. Contamination of sinus irrigation devices: a review of the evidence and clinical relevance. Am J Rhinol Allergy. 2012 May-Jun;26(3):201-3.

131. Williams GB, Ross LL, Chandra RK. Are bulb syringe irrigators a potential source of bacterial contamination in chronic rhinosinus- 
itis? Am J Rhinol. 2008 Jul-Aug;22(4):399-401.

132. Lee JM, Nayak JV, Doghramji LL, Welch KC, Chiu AG. Assessing the risk of irrigation bottle and fluid contamination after endoscopic sinus surgery. Am J Rhinol Allergy. 2010 May-Jun;24(3):197-9.

133. Welch KC, Cohen MB, Doghramji LL, Cohen NA, Chandra RK, Palmer JN, et al. Clinical correlation between irrigation bottle contamination and clinical outcomes in post-functional endoscopic sinus surgery patients. Am J Rhinol Allergy. 2009 Jul-Aug;23(4): 401-4.

134. Keen M, Foreman A, Wormald PJ. The clinical significance of nasal irrigation bottle contamination. Laryngoscope. 2010 Oct;120(10): 2110-4.

135. Nikolaou E, Mitsi E, Ferreira DM, Bartolo A, Leong SC. Assessing the ideal microwave duration for disinfection of sinus irrigation bottles: a quantitative study. Clin Otolaryngol. 2018 Feb;43(1): 261-6.

136. Morong S, Lee JM. Microwave disinfection: assessing the risks of irrigation bottle and fluid contamination. Am J Rhinol Allergy. 2012 Sep-Oct;26(5):398-400.

137. Shargorodsky J, Lane AP. What is the best modality to minimize bacterial contamination of nasal saline irrigation bottles? Laryngoscope. 2015 Jul;125(7):1515-6.

138. U.S. Food and Drug Administration. Is rinsing your sinuses with neti pots safe? [Internet]. Silver Spring (ML): U.S. Food and Drug Administration; 2021 [cited 2021 Jan 12]. Available from: http:// www.fda.gov/ForConsumers/ConsumerUpdates/ucm316375.htm.

139. Bogaert GA, Goeman L, de Ridder D, Wevers M, Ivens J, Schuermans A. The physical and antimicrobial effects of microwave heating and alcohol immersion on catheters that are reused for clean intermittent catheterisation. Eur Urol. 2004 Nov;46(5):641-6.

140. Merkus P, Ebbens FA, Muller B, Fokkens WJ. Influence of anatomy and head position on intranasal drug deposition. Eur Arch Otorhinolaryngol. 2006 Sep;263(9):827-32.

141. Saijo R, Majima Y, Hyo N,Takano H. Particle deposition of therapeutic aerosols in the nose and paranasal sinuses after transnasal sinus surgery: a cast model study. Am J Rhinol. 2004 Jan-Feb;18(1):1-7.

142. Olson DE, Rasgon BM, Hilsinger RL Jr. Radiographic comparison of three methods for nasal saline irrigation. Laryngoscope. 2002 Aug;112(8 Pt 1):1394-8.

143. Kayarkar R, Clifton NJ,WoolfordTJ.An evaluation of the best head position for instillation of steroid nose drops. Clin Otolaryngol Allied Sci. 2002 Feb;27(1):18-21.

144. Craig JR, Palmer JN, Zhao K. Computational fluid dynamic modeling of nose-to-ceiling head positioning for sphenoid sinus irrigation. Int Forum Allergy Rhinol. 2017 May;7(5):474-9. 